\title{
Performance Analysis of Wells Turbine Blades Using the Entropy Generation Minimization Method
}

\author{
Ahmed S. Shehata ${ }^{1,3^{*}}$, Khalid M. Saqr ${ }^{2}$, Qing Xiao ${ }^{1}$, Mohamed F. Shehadeh ${ }^{3}$, \\ Alexander Day ${ }^{1}$ \\ 1) Department of Naval Architecture, Ocean and Marine Engineering, University of \\ Strathclyde, Glasgow G4 OLZ, U.K \\ 2) Mechanical Engineering Department, College of Engineering and Technology \\ Arab Academy for Science Technology and Maritime Transport, P.O. 1029 AbuKir, Alexandria, \\ EGYPT \\ 3) Marine Engineering Department, College of Engineering and Technology \\ Arab Academy for Science Technology and Maritime Transport, P.O. 1029 AbuQir, Alexandria, \\ EGYPT \\ * Corresponding Author: Ahmed S. Shehata, E-mail address: \\ ahmed.mohamed-ahmed-shehata@strath.ac.uk
}

\begin{abstract}
Wells turbine concept depends on utilizing the oscillating air column generated over marine waves to drive a turbine. As a matter of fact, previous researches on the performance analysis of such turbine were based on the first law of thermodynamics only. Nonetheless, the actual useful energy loss cannot be completely justified by the first law because it does not distinguish between the quantity and the quality of energy. Therefore, the present work investigates the second law efficiency and entropy generation characteristics around different blades that are used in Wells turbine under oscillating flow conditions. The work is performed by using time-dependent CFD models of different NACA airfoils under sinusoidal flow boundary conditions. Numerical investigations are carried out for the incompressible viscous flow around the blades to obtain the entropy generation due to viscous dissipation. It is found that the value of second law efficiency of the NACA0015 airfoil blade is higher by approximately $1.5 \%$ than the second law efficiency of the NACA0012, NACA0020 and NACA0021 airfoils. Furthermore, it is found that the angle of attack radically affects the second law efficiency and such effect is quantified for NACA0015 for angle of attack ranging from $-15^{\circ}$ to $25^{\circ}$.
\end{abstract}

Keywords: Wells turbine; entropy generation; NACA airfoils; sinusoidal wave; CFD. 


\begin{tabular}{|c|c|}
\hline$A$ & Cross-sectional area of cylinder $\left(\mathrm{m}^{2}\right)$ \\
\hline$B$ & Cord of cylinder $(\mathrm{cm})$ \\
\hline$f$ & cycle frequency $(\mathrm{Hz})$ \\
\hline$F_{D}$ & In-line force acting on cylinder per unit length (gf) \\
\hline$K E$ & Kinetic Energy $(\mathrm{W} / \mathrm{K})$ \\
\hline$L$ & Blade Chord (m) \\
\hline$p$ & Pressure field $(\mathrm{Pa})$ \\
\hline$S_{g e n}$ & local entropy generation rate $\left(\mathrm{W} / \mathrm{m}^{2} \mathrm{~K}\right)$ \\
\hline$S_{G}$ & Global entropy generation rate $(\mathrm{W} / \mathrm{K})$ \\
\hline$S_{i j}$ & Mean strain rate \\
\hline$S_{t}$ & Thermal entropy generation rate $\left(\mathrm{W} / \mathrm{m}^{2} \mathrm{~K}\right)$ \\
\hline$S_{V}$ & Viscous entropy generation rate $\left(\mathrm{W} / \mathrm{m}^{2} \mathrm{~K}\right)$ \\
\hline$T_{o}$ & Reservoir temperature $(\mathrm{K})$ \\
\hline $\bar{u}_{i}$ & Reynolds Averaged velocity component in i direction $(\mathrm{m} / \mathrm{s})$ \\
\hline$V$ & Instantaneous Velocity $(\mathrm{m} / \mathrm{s})$ \\
\hline$V_{a}$ & highest speed of axial direction $(\mathrm{m} / \mathrm{s})$ \\
\hline$V_{o}$ & Initial velocity for computation $(\mathrm{m} / \mathrm{s})$ \\
\hline$W_{r e v}$ & Reversible work \\
\hline$\mu$ & Viscosity $(\mathrm{Kg} / \mathrm{ms})$ \\
\hline$\mu_{t}$ & Turbulent viscosity \\
\hline$\rho$ & Density $\left(\mathrm{Kg} / \mathrm{m}^{3}\right)$ \\
\hline$\sigma_{\epsilon}, \sigma_{k}$ & The turbulent Prandtl numbers for $\boldsymbol{\kappa}$ and $\boldsymbol{\varepsilon}$ respectively \\
\hline$\left(-\overline{\rho u_{i}^{\prime} u_{j}^{\prime}}\right)$ & Reynolds stress tensor \\
\hline
\end{tabular}

37 


\section{INTRODUCTION}

The major challenge facing oscillating water column systems is to find efficient and economical means of converting oscillating flow energy to unidirectional rotary motion, for driving electrical generators. A novel resolution for such challenge is the Wells turbine [1-4], see figure $1(a, b)$ due to its simple and efficient operation. The Wells turbine has already been applied in practice to gain energy from marine waves. In the past two decades, experimental research of Wells turbine has mainly focused on improving the turbine performance with emphasis on the overall operational characteristics. The airfoils sections that are used in Wells turbine have been extensively investigated in aeronautical applications. However, the operating conditions in Wells turbine are completely different from such of the aeronautical applications. In Wells turbine, the rotor contains multiple blades, which are confined by a shroud aiming at harnessing the flow momentum to drive the rotor with the maximum torque. The flow physics in such situations are still having several issues to investigate; besides, the dynamical complexity resulting from an oscillating water column driven by random irregular marine waves.

Second law analysis of energy conversion systems has become an important tool for optimization and development during the past decade. In Fact, the second law of thermodynamics is more reliable than the first law of thermodynamics analysis due to the limitation of the first law efficiency in a heat transfer engineering systems as well as heat transfer, mass transfer, viscous dissipation, etc. Moreover, the second law can be used as the sources of entropy generation $[5,6]$.Consequently, This work utilizes timedependent numerical models of different NACA four-digit series blade profile under oscillating flow conditions. Numerical investigations are carried out for the flow around Wells turbine blades using sinusoidal wave boundary conditions to perform as realistic characterization as possible of the flow field upstream and downstream of the turbine during the passage of the wave. The Gouy-Stodola theorem [7] has been used to compute the second law efficiency from the results of the numerical simulations. This theorem postulates the difference between reversible and actual works in any thermodynamic system which is the entropy generation in such system, as discussed later in section 4. Such theorem is the foundation for the entropy generation 
minimization method proposed by Bejan [8] to optimize finite size thermodynamic systems.

A thorough literature survey has revealed that the second law analysis of the oscillating flow around wells turbine has not been conducted before. However, this section briefly reviews the most relevant studies to accentuate the scope of the present work. In a number of previous studies, it is concluded that the delay of stall onset contributes in improving Wells turbine performance. This delay can be achieved by setting guide vanes on the hub near the rotor[9].

As far as the running and starting characteristics of the Wells turbine are concerned, Wells turbine with 3D guide vanes are superior to those with $2 \mathrm{D}$ guide vanes or without guide vanes[10,11]. Furthermore, the presence of end plates is investigated experimentally and numerically by $[12,13]$ where they conclude that the Wells turbine with end plates is superior to those of the original Wells turbine(which was investigated also in this work) because the peak efficiency and the stall margin increases by approximately $4 \%$ and its characteristics are dependent on the size and position of end plate.

Three dimensional numerical simulations are performed by Thakker et al [14] in order to analyze the performance of a Wells turbine with CA9 blade profile, a maximum efficiency of $70 \%$ is obtained. Moreover, Kim et al [15] uses numerical simulation to study the effect of the blade sweep on the performance of a Wells turbine using either NACA0020 or CA9 blade profiles. They were found that the performance of the Wells turbines with NACA0020 and the CA9 blades are influenced by the blade sweep. As the optimum rotor shape for a NACA0020 blade, a blade sweep ratio 35\% is identified to deliver the optimum performance. In general, the overall turbine performance for the NACA0020 is better than such of the CA9, Also, Takao et al [16], presents experimentally the suitable choice the sweep ratio of 0.35 for the cases of CA9 and HSIM 15-262123-1576. In another study [17], the characteristics of a Wells turbine with NACA0021 constant chord blades are investigated. They find from the numerical results that the wakes behind the turbine blades merge rigorously in the portion of radius ratio from 0.45 to 1.0 , which leads the turbine to stall. 
One and two stage Wells turbines involving symmetric airfoils and NonSymmetric airfoils are investigated by Mohamed [18, 19]. Numerical optimization procedure has been carried out to optimize the performance of the turbine as a function of the non-dimensional gap between the two rotors. It is leading to an optimal value of the non-dimensional gap (The distance between the two stages / the blade chord) near 0.85 when considering the operating range. Moreover, the Evolutionary Algorithms are used to estimate the optimum shape with an increase of efficiency (by $2.1 \%$ ) and of tangential force coefficient (by 6\%), compared to the standard NACA 2421, as well as the one-stage the optimum shape with an increase of efficiency (by 1\%) and of tangential force coefficient (by 11.3\%), compared to the standard NACA 0021.

On the other hand, the hysteretic characteristics of monoplane and biplane have been studied in a number of studies [20-26]. The objective of such works is mainly to investigate the aerodynamic losses of Wells turbine. It is found that for the biplane, the hysteretic behavior is similar to that of the monoplane at lower angles of attack, but the hysteretic loop similar to the dynamic stall is observed at higher angles of attack. Exergy analysis is performed using the numerical simulation for steady state biplane Wells turbines [27] where the upstream rotor has a design point second law efficiency of $82.3 \%$ although the downstream rotor second law efficiency equals $60.7 \%$.

Most of the researchers who have investigated the performance of different airfoils design and different operational condition have analyzed the problem using only the parameter of first law of thermodynamic that lead to several contradicting conclusions that can be observed, for example, in [28]. This shows that the use of two twin rotors rotating in the opposite direction to each other is an efficient means of recovering the swirl kinetic energy without the use of guide vanes. On quite the opposite, a contra-rotating W-T which is investigated in [29], it is found to have a lower efficiency than a biplane or monoplane W-T with guide vanes. Another example, we can observe this contradiction also in the comparison between the performances of the Wells turbines in four different kinds of blade profile (NACA0020; NACA0015; CA9; and HSIM 15-262123-1576). Which, the blade profile of (NACA0020) have the best performance according to the result of $[16,30]$, but, according to the result of [31] 
the blade profile of (NACA0015) achieve best result. Finally, the rotor geometry preferred was the blade profile of (CA9) according to the result of $[32,33]$.

It is essential to look at the second law of thermodynamic to form a deeper understanding, since it has shown very promising result in many applications, like wind turbine in [34-38], Radial Compressor Stage [39], pipe flow [40], thermal power plants [6], and Rotating disk [5].

The objective of the present work is essentially to investigate the entropy generation, due to viscous dissipation, around Wells turbine airfoils in twodimensional unsteady flow configurations. The research aims to use the entropy generation due to viscous dissipation around a Wells turbine blade as very sensitive judged parameter on the turbine performance for any change in terms of the operating condition (the flow Reynolds number up to $2.4 \times 10^{5}$ and the airfoil angle of attack from -15 to 25 degree), the blade design (four different airfoils) and flow direction (sinusoidal wave with compression and suction cycle). This work is limited to four airfoils namely NACA0012, NACA0015, NACA0020 and NACA0021. These airfoils are common to use in Wells turbine applications.

\section{MATHMEATICAL MODEL AND NUMERICAL APPROACH}

The mathematical model consists of the governing equations of turbulent incompressible unsteady flow in two-dimensional generalized coordinates, which can be written in vector notations as[41]:

Continuity: $\frac{\partial}{\partial t}+\frac{\partial}{\partial x_{i}}\left(\bar{u}_{i}\right)=0$

RANS: $\quad \rho \frac{\partial \overline{u_{i}}}{\partial t}+\frac{\partial}{\partial x_{i}}\left(\rho \bar{u}_{i} \bar{u}_{j}\right)=-\frac{\partial p}{\partial x_{j}}+\frac{\partial}{\partial x_{j}}\left[\mu\left(\frac{\partial \bar{u}_{i}}{\partial x_{j}}+\frac{\partial \bar{u}_{j}}{\partial x_{i}}-\frac{2}{3} \delta_{i j} \frac{\partial \bar{u}_{j}}{\partial x_{i}}\right)\right]+\frac{\partial}{\partial x_{j}}\left(-\overline{\rho u_{i}^{\prime} u_{j}^{\prime}}\right)$

and turbulent flow is modeled using the Realizable k-e model, Transport equation of turbulent kinetic energy $(\mathrm{k})$

$\frac{\partial}{\partial t}(\rho k)+\rho \frac{\partial}{\partial x_{i}}\left(U_{i} k\right)=\frac{\partial}{\partial x_{j}}\left[\left(\mu+\frac{\mu_{T}}{\sigma_{k}}\right) \frac{\partial^{164}}{\partial x_{j}} k\right]_{6}+\mu_{T} S^{2}-\rho \varepsilon$ 
166 Specific dissipation rate equation is:

167

169

$$
\frac{\partial}{\partial t}(\rho \varepsilon)+\rho \frac{\partial}{\partial x_{i}}\left(U_{i} \varepsilon\right)=\frac{\partial}{\partial x_{j}}\left[\left(\mu+\frac{\mu_{T}}{\sigma_{\varepsilon}}\right) \frac{\partial}{\partial x_{j}} \varepsilon\right]+C_{1} \rho S_{\varepsilon}-\mathbb{C} 6 \frac{\varepsilon^{2}}{k+\sqrt{v \varepsilon}}
$$

$$
\text { Where } \quad C_{1}=\max \left(0.43, \frac{\eta}{\eta+5}\right), \quad C_{2}=1.9
$$

$$
C_{\mu}=\frac{1}{A_{974}+A_{s} U^{*} \frac{k}{\varepsilon}}
$$

175 Where

$$
A_{0}=4.0, U^{*}=\sqrt{S_{i j} S_{i j}+\Omega_{i j} \Omega_{i j}}, A_{s}=\sqrt{6} \cos \left(\frac{1}{3} \arccos (\sqrt{6} W)\right), W=\frac{\sqrt{8} S_{i j} S_{j k} S_{k i}}{S^{3}}
$$

and the vorticity tensor $\Omega_{i j}=\frac{1}{2}\left(\frac{\partial \overline{u_{i}}}{\partial x_{j}}-\frac{\partial \overline{u_{j}}}{\partial x_{i}}\right)$

180

181 where $\bar{u}$ is the Reynolds averaged velocity vector. The present study adopts one and two-equation turbulence models to close the Reynolds stress term $\left(-\overline{\rho u_{i}^{\prime} u_{j}^{\prime}}\right)$ of the RANS equation [42] as shown in the following section. The transport equations of such models can be found in turbulence modeling texts such as [43]. The second law of thermodynamic defines the net-work transfer rate $\dot{W}$ as [8]:

$$
\dot{W}=W_{r e v}-T_{o} S_{g e n}
$$

It is possible to express the irreversible entropy generation in terms of the derivatives of local flow quantities in the absence of phase changes and chemical reactions. The two dissipative mechanisms in viscous flow are the strain-originated dissipation and the thermal dissipation Which correspond to a viscous and a thermal entropy generation respectively [39]. Thus, it can be written,

$$
S_{g e n}=S_{V}+S_{t h}
$$


194 dissipation term vanishes. The local viscous irreversibilities therefore can be expressed 195 as:

$196 S_{V}=\frac{\mu}{T_{o}} \phi$

197 where $\phi$ is the viscous dissipation term, that is expressed in two dimensional Cartesian 198 coordinates as [39]:

199

$\phi=2\left[\left(\frac{\partial u}{\partial x}\right)^{2}+\left(\frac{\partial v}{\partial y}\right)^{2}\right]+\left(\frac{\partial u}{\partial y}+\frac{\partial v}{\partial x}\right)^{2}$

200

and the global entropy generation rate is hence expressed as:

$201 S_{G}=\iint_{x y} S_{V} d y d x$

202

and finely the second law efficiency is defined as :

$203 \quad \eta_{S}=\frac{K E}{K E+S_{G}}$

204 where $K E=\frac{1}{2} V^{2}$

205

but the efficiency in first law of thermodynamics $\left(\eta_{f}\right)$ is defined as:

206

207

$$
\eta_{f}=\frac{\text { Net Output }}{\text { Total work Input }}
$$

\subsection{Numerical Model Details}

209

The computational domain is discretized to Cartesian structured finite volume cells using GAMBIT code. Drichlet boundary conditions are applied on the domain for the solution of momentum and continuity equations. The application of such boundary condition types [21, 44-46] matches the GreenGauss cell based evaluation method for the gradient terms used in the solver (ANSYS FLUENT). Numerous tests accounting for different interpolation schemes used to compute cell face values of the flow field variables, the variables of governing equation which are velocity and pressure, as well as convergence tests have been undertaken. The second order upwind interpolation scheme is used in this work because it yields results which are approximately 
similar to such yielded by third order MUSCL scheme in the present situation. It is also found that the solution reaches convergence when the scaled residuals approaches $1 \times 10^{-5}$. At such limit, the flow field variables holds constant values with the application of consecutive iterations. Figure (2); show the dimensions of whole computational domain and location of airfoil. Figure (3) show the grid distribution near the wall of the airfoil.

The axial flow of Wells Turbine is modeled as a sinusoidal wave in this simulation. Therefore, Inlet boundary conditions are set to change as time. In order to apply the inlet boundary condition, inlet velocity with periodic function (see figure 4) is generated as follows.

$$
V=V_{o}+V_{a}(\sin 2 \pi f t)
$$

where $t$ is time period 6.7 seconds are set as one period in this simulation considering to the literature survey [22, 23, 33]. Time step is set as 0.00009 second in order to satisfy CFL (Courant Friedrichs Lewy) [47] condition equal to 1 . the sinusoidal wave condition create various Reynolds number up to $2.4 \times 10^{5}$ and this maximum value which is taken from many references such as $[13,18,20-23,25,48,49]$. Regarding the angle of attack, it covers wide range of angles of attack in both directions (positive and negative) but it doesn't need more than this value because the stall condition [50].

\subsection{Numerical Model Validation}

In order to ensure that the numerical model is free from numerical errors, several grids are tested to estimate the number of grid cells required to establish a grid-independent test. Table 1 shows the specifications of different grids used in such test. Figure 5 shows the pressure coefficient $\left(\mathrm{C}_{\mathrm{p}}\right)$ distribution on the upper and lower surfaces of the airfoil as computed by the four grids. Grid C and D have the same result, but the latter one required less time. So, Grid C is chosen to conduct the analysis presented hereafter.

Many turbulence models are used to model the oscillating flow around the object in order to determine the model which gives the best agreement with 

the Realizable $k-\varepsilon$ model but the latter one required less time [52]. As For the near-wall treatment in both K-epsilon and S-A models have used the log law of the wall but for k-omega models have used y plus less than one. This experimental data for unsteady forces acting on a square cylinder in oscillating flow with nonzero mean velocity are measured [51] where the oscillating air flows are generated by a unique AC servomotor wind tunnel. The generated velocity histories are almost exact sinusoidal waves. The measured unsteady $F_{D}$ is computed from the Morison equation for the in-line force acting on the cylinder per unit length:

$$
F_{D}=\frac{1}{2} \rho B C_{D}|U| U+\rho A \widetilde{C}_{D} \dot{U}
$$

where $\dot{U}=d U / d t$ and the non-dimensional coefficient $\widetilde{C}_{D}$ is the inertia coefficient of the unsteady in-line force. This non-dimensional coefficient is evaluated depend on $[53,54]$.

This data is the most experimental data that have available information for the sinusoidal flow condition to validate our work; therefore, it is adopted in the following simulation cases. Figure 6 (a), (b) show an excellent agreement between measured drag force from reference and calculated drag force from CFD at two different frequency.

\section{RESULTS AND DISCUSSION}

\subsection{Evaluation of the second law efficiency of different NACA airfoils}

The numerical simulations are used to obtain local entropy viscosity predictions of the different airfoil sections. Figure 7(a) and (b) highlight the entropy behavior when a flow is accelerating in compression and suction cycle. Consequently, the entropy generation ratio various with the Reynolds number at certain angle of attack equal to 2 degree. The change of Reynolds number values is due to using sinusoidal wave boundary conditions. At low values of Reynolds number the stall condition occur at small value of angle of attack[50]. Hence, 2 degree angle of attack is chosen to avoid the stall condition. 

of Reynolds number in this study can be controlled by the value of velocity while keeping the other parameters constant.

$$
\operatorname{Re}=\frac{V L \rho}{\mu}
$$

The Reynolds number has radical effect on the entropy generation. This is obvious in the accelerating flow in compression and suction cycle in Figure 7 (a, b), where Reynolds number increase from $6 \times 10^{4}$ to $1.2 \times 10^{5}$. As a result, the global entropy generation rate (i.e. integral) has increased correspondingly for more than two folds of all airfoils. However, when Reynolds number has increased further to $1.7 \times 10^{5}\left(2 \times 10^{5}\right.$ for NACA0012 at compression cycle $)$ the global entropy generation rate exhibited unintuitive values ranging from $50 \%$ less to $40 \%$ lower than the corresponding value at Reynolds number equal to $1.2 \times 10^{5}$ for all airfoils. The reason behind such phenomena can be attributed to the nonlinear complexity of the viscous dissipation term (equation 9) where both the square of mean rate of strain and velocity divergence contributes to the local viscous irreversibilities. This phenomenon suggests that possible existence of critical Reynolds number at which viscous irreversibility takes minimum values. At high Reynolds number (greater than $2 \times 10^{5}$ ) the change in velocity value, see equation 14 , is smaller than low Reynolds number. Where, at 120000 Reynolds number the velocity equal to $17.5 \mathrm{~m} / \mathrm{s}$, then it increases to $24.8 \mathrm{~m} / \mathrm{s}$ at 170000 Reynolds number (41\%increase rate). After that, it reaches to 200000 Reynolds number with velocity equal to 30.3 $\mathrm{m} / \mathrm{s}$ (22\%increase rate). On the other hand, at high Reynolds number (230000) the velocity equal to $33.8 \mathrm{~m} / \mathrm{s}$ (10\%increase rate). Then, at 240000 Reynolds number the velocity reach to maximum value equal to $35.04 \mathrm{~m} / \mathrm{s}$ ( $3 \%$ increase rate), see Figure 4. This leads to smaller change in flow field and entropy generation. The last one was dependent on velocity analysis.

However, in figure $8(\mathrm{a}, \mathrm{b})$ for decelerating flow in compression and suction cycle when Reynolds number, in Figure $(8, a)$, is decreased further to $1.2 \times 10^{5}$ the global entropy generation rate exhibited unintuitive values ranging from 94\% (NACA0021, NACA0020) less to 59\% (NACA0015) and 15\% for (NACA0012) 
higher than the corresponding value at Reynolds number equal to $1.7 \times 10^{5}$. For decelerating flow in suction cycle the global entropy generation rate, at Reynolds number equal to $1.2 \times 10^{5}$, exhibited unintuitive values ranging from $135 \%$ (NACA0012) less to 83\% (NACA0020) and 68\% (NACA0021, NACA0015) which is higher than the corresponding value at Reynolds number equal to $1.7 \times 10^{5}$. Then, when Reynolds number is decreased further to a minimum value the global entropy generation rate is decreased also to minimum value and not equal to zero. From figure 7 and 8 , at maximum Reynolds number, the NACA0012 give lower entropy generation rate than other airfoil. From figure 9, it is concluded that the NACA0015 give lower maximum value for the global entropy generation rate than other airfoil in both cycles. The NACA0015 airfoil section gives less average value ranging from $20 \%$ less to $10 \%$ of the global entropy generation rate during the sinusoidal wave cycle see figure 10 . To confirm these results we have made a comparison between the second law efficiency for four different airfoils at compression and suction cycle (figure 11) and also for the total average efficiency during the sinusoidal wave cycle (figure 12), NACA0015 gives best efficiency when it is compared with other airfoils in both compression and suction cycle and therefore in total sinusoidal wave cycle ranging from $2 \%$ less to $1 \%$. In four different airfoils and at certain angle of attack, the efficiency for compression cycle higher than suction cycle ranging from $1 \%$ less to $0.3 \%$. Equation (17) is defining the exergy value, which can be written as:

$$
\text { Exergy }=K E+S_{G}
$$

Contours of Exergy around the blade of NACA0015 for angle of attack 2 degree at different time and different velocity along the sinusoidal wave can be seen in figure (13) that the positive value of velocity refers to compression cycle and the negative value refers to suction cycle. From this figure it can be observed that as the velocity increase the value of exergy around the blade increase, otherwise, the leading and trailing edge always have the lowest value, but at compression cycle the area around the trailing edge has lower value than the leading edge, and in the suction cycle the area around the leading edge has lower value than trailing one. 


\subsection{Effect of the angle of attack on entropy generation}

The increase of angle of attack has a direct effect to the entropy generation in the flow over the airfoil which is similar to the effect of Reynolds number. However, as shown in figure 14(a) and (b), NACA0015 airfoil has a different entropy generation signature for different angles of attack listed in table 2. For accelerating flow in compression cycle, Figure 14 (a) at Reynolds number equal to $1.2 \times 10^{5}$ the maximum value of global entropy generation rate occurs due to 2 degree angle of attack but the minimum value of it occurs due to - 15 degree angle of attack. The 17 degree angle of attack gives maximum global entropy generation rate at $1.7 \times 10^{5}$ Reynolds number, and the minimum value occurs due to -11 degree at the same Reynolds number. Finally, at Reynolds number equal to $2.3 \times 10^{5}$ and $2.4 \times 10^{5}$ the maximum global entropy generation rate occurs due to 17 degree and the minimum value occurs due to 5 degree.

The trend of global entropy generation rate at suction cycle is different from the compression cycle at various angles which can be seen in figure 14 (b). For decelerating flow in suction cycle at Reynolds number equal to $1.7 \times 10^{5}$, the maximum global entropy generation rate occurs at 5 degree angle of attack and the minimum value occurs due to 25 degree. For Reynolds number equal to $1.2 \times 10^{5}$ the maximum global entropy generation rate occurs due to 2 degree angle of attack and the minimum value due to 25 degree. Low angles of attack around zero, both positive and negative direction have higher global entropy generation rate and lower entropy efficiency except at 17 degree so we can note that there is unexpected increase in the value of global entropy generation rate accompanied by a lack of the second law efficiency, see figure 15 and 16. As For angle of attack from -5 to 5 degree the entropy efficiency for compression cycle higher than the suction cycle, but when the angle of attack increase in both directions the efficiency for suction cycle exceeds the compression cycle, see figure 17. At same angle of attack but in different direction, the positive direction gives higher efficiency than the negative one. For example, the second law efficiency for 5 degree higher approximately $0.5 \%$ than -5 degree and approximately $0.1 \%$ between 11 and -11 degree and finally $0.3 \%$ between 15 and -15 degree. 


\section{CONCLUSIONS}

Second law analysis of Wells turbine requires accurate estimation of flow irreversibilities around the turbine blades. Two-dimensional incompressible unsteady flow simulations of different airfoils reveals that the geometry and the operating conditions have radical effects on the global entropy generation rate in the flow around turbine airfoil. The main conclusions are summarized as follows.

1- The relationship between the Reynolds number and the global entropy generation rate haven't a direct correlation but when compare between four airfoils at certain angle of attack the maximum global entropy generation rate occurs at Reynolds

\section{Acknowledgements}

The authors would like to acknowledge the support provided by the Department of Naval Architecture, Ocean and Marine Engineering at Strathclyde University and the 
Department of marine Engineering at Arab Academy for Science, Technology and Maritime Transport.

\section{REFERENCES}

[1] T.J.T.e.a. Whittaker, The Queen's university of Belfast Axisymmetric and Multiresonant Wave Energy Converters, Trans. ASME. J. Energy Resources Tech., 107 (1985) pp. 74-80.

[2] T.J.T.a.M. Whittaker, F. A., Design Optimisation of Axisymmetric Tail Tube Buoys, in: IUTAM, Symposium on Hydrodynamics of Ocean Wave Energy Conversion, Lisbon,July., 1985.

[3] T.J.J. Whittaker, McIlwain, S. T. and Raghunathan, S. , Islay Shore Line Wave Power Station, Proceedings European Wave Energy Symposium., Paper G6, Edinburgh. (1993).

[4] S. Raghunathan, Theory and Performance of Wells Turbine, Queen's University of Belfast, Rept. WE/80/13R (1980).

[5] M.M. Rashidi, M. Ali, N. Freidoonimehr, F. Nazari, Parametric Analysis and Optimization of Entropy Generation in Unsteady MHD Flow over a Stretching Rotating Disk Using Artificial Neural Network and Particle Swarm Optimization Algorithm, Energy, 55 (2013) 497-510.

[6] S.C. Kaushik, V.S. Reddy, S.K. Tyagi, Energy and Exergy Analyses of Thermal Power Plants: A Review, Renewable and Sustainable Energy Reviews, 15 (2011) 18571872.

[7] A. Bejan, Entropy Generation Minimization: The Method of Thermodynamic Optimization of Finite-Size Systems and Finite-Time Processes, Taylor \& Francis, (1995).

[8] A. Bejan, Entropy Generation Minimization- The New Thermodynamics of FiniteSize Devices and Finite-Time Processes, Applied Physics Reviews, (1996).

[9] L.M.C. Gato, R. Curran, The Energy Conversion Performance of Several Types of Wells Turbine Designs, Proceedings of the Institution of Mechanical Engineers, Part A: Journal of Power and Energy, 211 (1997) 133-145.

[10] T. Setoguchi, Effect of Guide Vane Shape on the Performance of a Wells Turbine, Renewable Energy, 23 (2001) 1-15.

[11] M. Takao, T. Setoguchi, T.H. Kim, K. Kaneko, M. Inoue, The Performance of a Wells Turbine with 3D Guide Vanes, International Journal of Offshore and Polar Engineering, 11 (2001) 72-76.

[12] M. Mamun, Y. Kinoue, T. Setoguchi, K. Kaneko, A.K.M.S. Islam, Improvement af the Performance of the Wells Turbine by using a Very Thin Elongated Endplate at the Blade Tip, in: the 3rd BSME-ASME International Conference on Thermal Engineering, ASME, Dhaka, Bangladesh, 2006.

[13] M. Takao, T. Setoguchi, Y. Kinoue, K. Kaneko, Wells Turbine with End Plates for Wave Energy Conversion, Ocean Engineering, 34 (2007) 1790-1795.

[14] A. Thakker, P. Frawley, E.S. Bajeet, Numerical Analysis of Wells Turbine Performance Using a 3D Navier Stokes Explicit Solver, in: International Offshore and Polar Engineerbtg Conference, Stavanger, Norway, 2001. 

Numerical Analysis for Unsteady Flow Characteristics of the Wells Turbine, in: International Offshore and Polar Engineering Conference, The International Society of Offshore and Polar Engineers, Kitakyushu, Japan, 2002, pp. 694-699. [16] T. Setoguchi, M. Takao, K. Itakura, M. Mohammad, K. Kaneko, A. Thakker, Effect of Rotor Geometry on the Performance of Wells Turbine, in: The Thirteenth International Offshore and Polar Engineering Conference, The International Society of Offshore and Polar Engineers, Honolulu, Hawaii, USA, 2003, pp. 374-381.

[17] T.S. Dhanasekaran, M. Govardhan, Computational Analysis of Performance and Flow Investigation on Wells Turbine for Wave Energy Conversion, Renewable Energy, 30 (2005) 2129-2147.

[18] M.H. Mohamed, G. Janiga, D. Th'evenin, Performance Optimization of a Modified Wells Turbine using Non-Symmetric Airfoil Blades, in: Turbo Expo 2008: Power for Land, Sea and Air GT, ASME, Berlin, Germany, 2008.

[19] M.H. Mohamed, Design Optimization of Savonius and Wells Turbines, in, University of Magdeburg,Germany, Germany, 2011.

[20] Y. Kinoue, T.H. Kim, T. Setoguchi, M. Mohammad, K. Kaneko, M. Inoue, Hysteretic Characteristics of Monoplane and Biplane Wells Turbine for Wave Power Conversion, Energy Conversion and Management, 45 (2004) 1617-1629.

[21] M. Mamun, Y. Kinoue, T. Setoguchi, T.H. Kim, K. Kaneko, M. Inoue, Hysteretic Flow Characteristics of Biplane Wells Turbine, Ocean Engineering, 31 (2004) 14231435.

[22] T. Setoguchi, Y. Kinoue, T.H. Kim, K. Kaneko, M. Inoue, Hysteretic Characteristics of Wells Turbine for Wave Power Conversion, Renewable Energy, 28 (2003) 2113-2127.

[23] T.H. Kim, T. Setoguchi, Y. Kinoue, K. Kaneko, M. Inoue, Hysteretic Characteristics of Wells Turbine for Wave Power Conversion, in: The Twelfth International Offshore and Polar Engineering Conference, The International Society of Offshore and Polar Engineers, Kitakyushu, Japan, 2002, pp. 687-693.

[24] T.M. Setoguchi T, Kaneko K., Hysteresis on Wells Turbine Characteristics in Reciprocating Flow, International Journal of Rotating Machinery, 4 (1998) 17-24. [25] Y. Kinoue, T. Setoguchi, T.H. Kim, K. Kaneko, M. Inoue, Mechanism of Hysteretic Characteristics of Wells Turbine for Wave Power Conversion, Journal of Fluids Engineering, 125 (2003) 302.

[26] M. Mamun, The Study on the Hysteretic Characteristics of the Wells Turbine in a Deep Stall Condition, in: Energy and Material Science Graduate School of Science and Engineering, Saga University, Japan, 2006, pp. 141.

[27] S. Shaaban, Insight Analysis of Biplane Wells Turbine Performance, Energy Conversion and Management, 59 (2012) 50-57.

[28] L.M.C. Gato, R. Curran, Performance of the Contrarotating Wells Turbine, International Journal of Offshore and Polar Engineering, 6 (1996) 68-75.

[29] M. Folley, R. Curran, T. Whittaker, Comparison of LIMPET Contra-rotating Wells Turbine with Theoretical and Model Test Predictions, Ocean Engineering, 33 (2006) 1056-1069.

[30] Y. Kinoue, T. Setoguchi, T. Kuroda, K. Kaneko, M. Takao, A. Thakker, Comparison of Performances of Turbines for Wave Energy Conversion, Journal of Thermal Science, 12 (2003) 323-328. 

Performance of a Large-scale Wells Turbine for Wave-energy Conversion, International Journal of Sustainable Energy, 25 (2006) 53-61. Turbine under Unidirectional Sinusoidal and Real Sea Flow Conditions, International Journal of Rotating Machinery, 2007 (2007) 1-9.

[33] A. Thakker, R. Abdulhadi, The Performance of Wells Turbine Under BiDirectional Airflow, Renewable Energy, 33 (2008) 2467-2474.

[34] K. Pope, I. Dincer, G.F. Naterer, Energy and Exergy Efficiency Comparison of Horizontal and Vertical Axis Wind Turbines, Renewable Energy, 35 (2010) 2102-2113. [35] O. Baskut, O. Ozgener, L. Ozgener, Effects of Meteorological Variables on Exergetic Efficiency of Wind Turbine Power Plants, Renewable and Sustainable Energy Reviews, 14 (2010) 3237-3241.

[36] A.M. Redha, I. Dincer, M. Gadalla, Thermodynamic Performance Assessment of Wind Energy Systems: An Application, Energy, 36 (2011) 4002-4010.

[37] O. Ozgener, L. Ozgener, Exergy and Reliability Analysis of Wind Turbine Systems: A Case Study, Renewable and Sustainable Energy Reviews, 11 (2007) 18111826.

[38] O. Baskut, O. Ozgener, L. Ozgener, Second Law Analysis of Wind Turbine Power Plants: Cesme, Izmir Example, Energy, 36 (2011) 2535-2542.

[39] C.L. Iandoli, 3-D Numerical Calculation of the Local Entropy Generation Rates in a Radial Compressor Stage, International journal of thermodynamics, 8 (2005) 83-94. [40] E.M. Wahba, A Computational Study of Viscous Dissipation and Entropy Generation in Unsteady Pipe Flow, Acta Mechanica, 216 (2010) 75-86. [41] S.D. Launder Be, The Numerical Computation of Turbulent Flows, Computer Methods in Applied Mechanics and Engineering, 3 (1974) 269-289. [42] D.C. Wilcox, Turbulence Modeling for Computational Fluid Dynamics, DCW Industries, Incorporated, 2006. [43] C. Hirsch, Numerical Computation of Internal and External Flows: The Fundamentals of Computational Fluid Dynamics, Elsevier Science, 2007.

[44] R. Starzmann, T. Carolus, Model-Based Selection of Full-Scale Wells Turbines for Ocean Wave Energy Conversion and Prediction of their Aerodynamic and Acoustic Performances, Proceedings of the Institution of Mechanical Engineers, Part A: Journal of Power and Energy, 228 (2013) 2-16.

[45] M.H. Mohamed, S. Shaaban, Optimization of Blade Pitch Angle of an Axial Turbine Used for Wave Energy Conversion, Energy, 56 (2013) 229-239.

[46] M. Torresi, S.M. Camporeale, G. Pascazio, Detailed CFD Analysis of the Steady Flow in a Wells Turbine Under Incipient and Deep Stall Conditions, Journal of Fluids Engineering, 131 (2009) 071103.

[47] C.A.K. DE Moura, Carlos S., The Courant-Friedrichs-Lewy (CFL) Condition: 80 Years After Its Discovery, 1 ed., Birkhäuser Basel, Boston, 2013.

[48] M.H. Mohamed, S. Shaaban, Numerical Optimization of Axial Turbine with Selfpitch-controlled Blades used for Wave Energy Conversion, International Journal of Energy Research, (2013) n/a-n/a. [49] M.H. Mohamed, G. Janiga, E. Pap, D. Thévenin, Multi-objective Optimization of the Airfoil Shape of Wells Turbine used for Wave Energy Conversion, Energy, 36 (2011) 438-446. 
545 [50] R.E. Sheldahl, P.C. Klimas, Aerodynamic Characteristics of Seven Symmetrical

546 Airfoil Sections Through 180-Degree Angle of Attack for Use in Aerodynamic Analysis

547 of Vertical Axis Wind Turbines, in: Sandia National Laboratories energy report, the

548 United States of America, 1981, pp. 118.

549 [51] T. Nomura, Y. Suzuki, M. Uemura, N. Kobayashi, Aerodynamic Forces on a

550 Square Cylinder in Oscillating Flow with Mean Velocity, Journal of Wind Engineering

551 and Industrial Aerodynamics, 91 (2003) 199-208.

552 [52] A.S. Shehata, K.M. Saqr, M. Shehadeh, Q. Xiao, A.H. Day, Entropy Generation

553 Due to Viscous Dissipation around a Wells Turbine Blade: A Preliminary Numerical

554 Study, Energy Procedia, 50 (2014) 808-816.

555 [53] T.M. A. Okajima, S. Kimura, Force Measurements and Flow Visualization of

556 Circular and Square Cylinders in Oscillatory Flow, Proc. JSME B 63 (615), (1997) 58-

55766.

558 [54] R.D. Blevins, Flow-Induced Vibration, 2nd Edition ed., Van Nostrand Reinhold,

559 New York, 1990.

560 


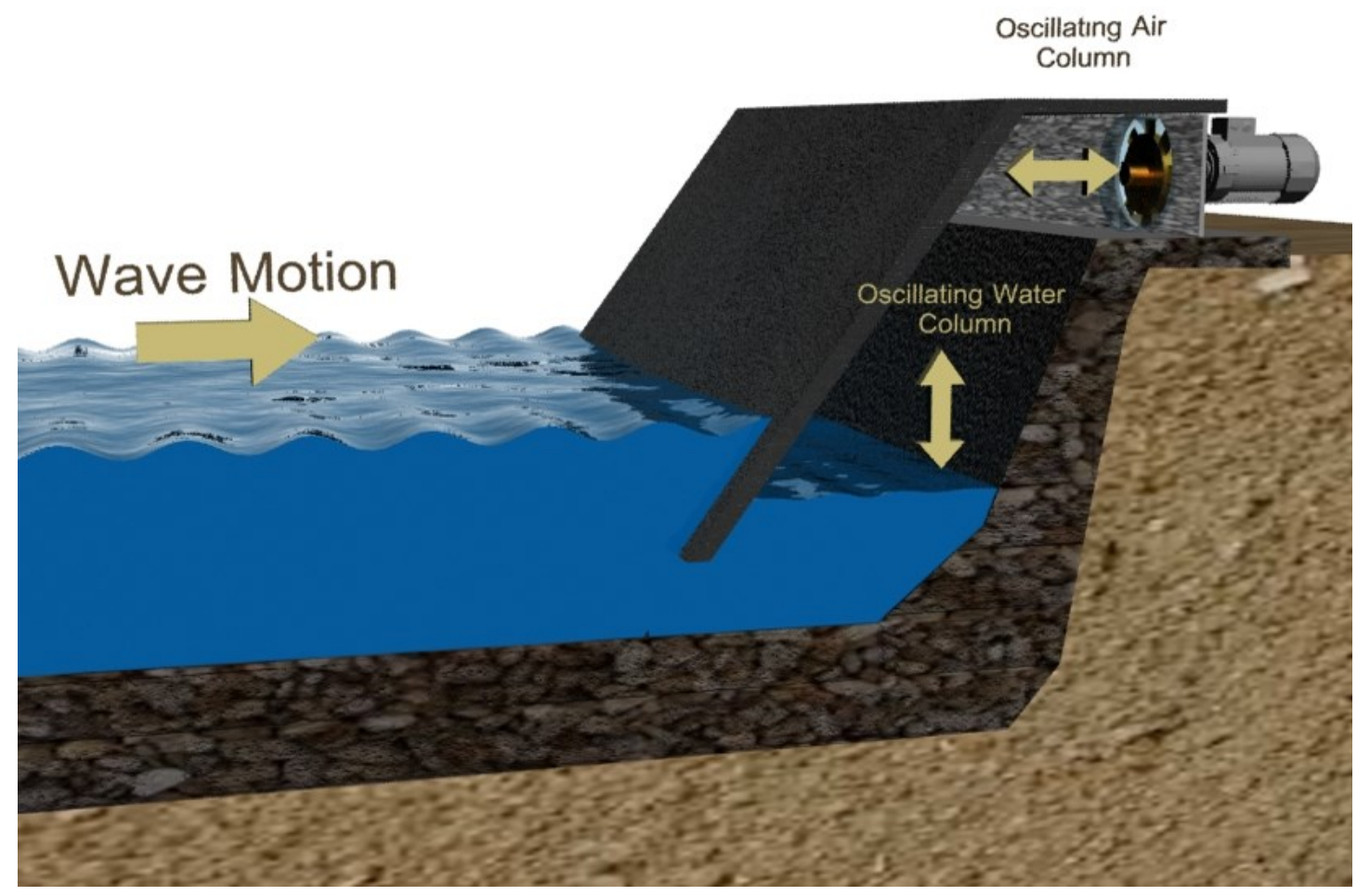

Figure 1.a. An illustration of the principle of operation of OWC system, where the wave motion is used to drive a turbine through the oscillation of air column.

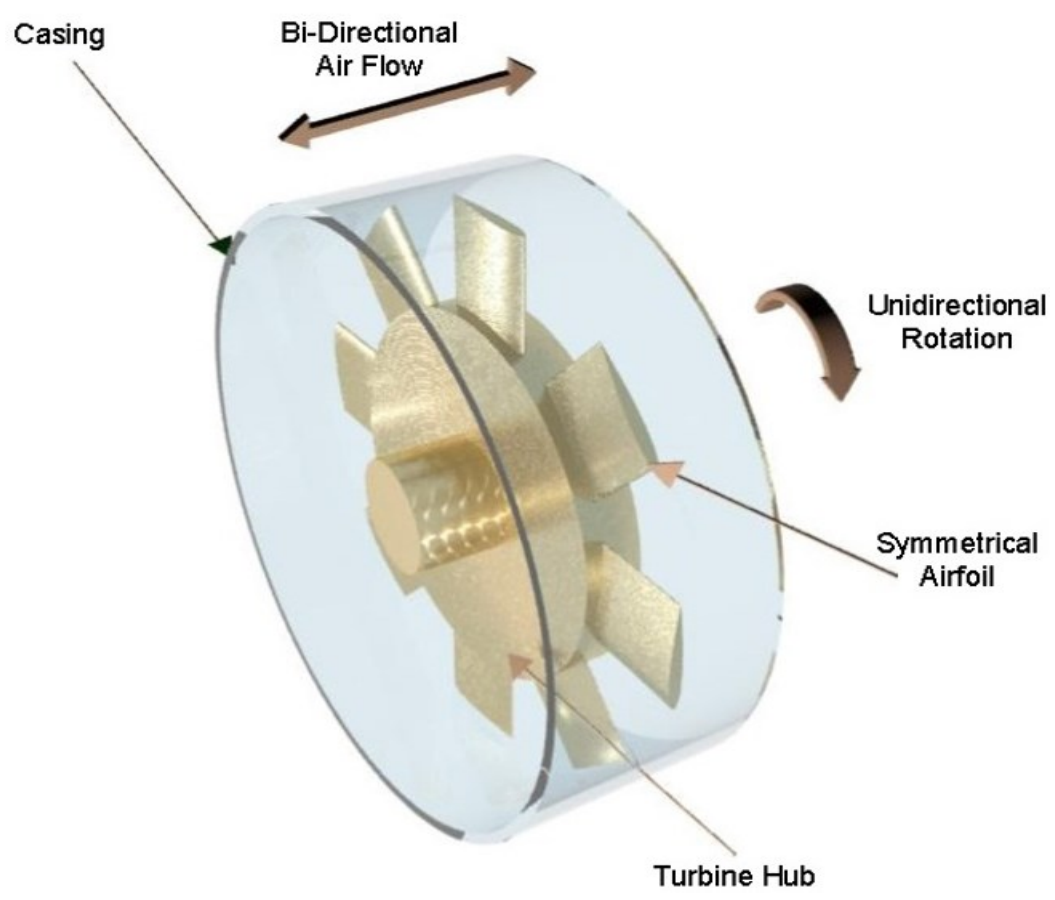

Figure 1.b. Typical structure of $\mathrm{W}-\mathrm{T}$ rotor. 


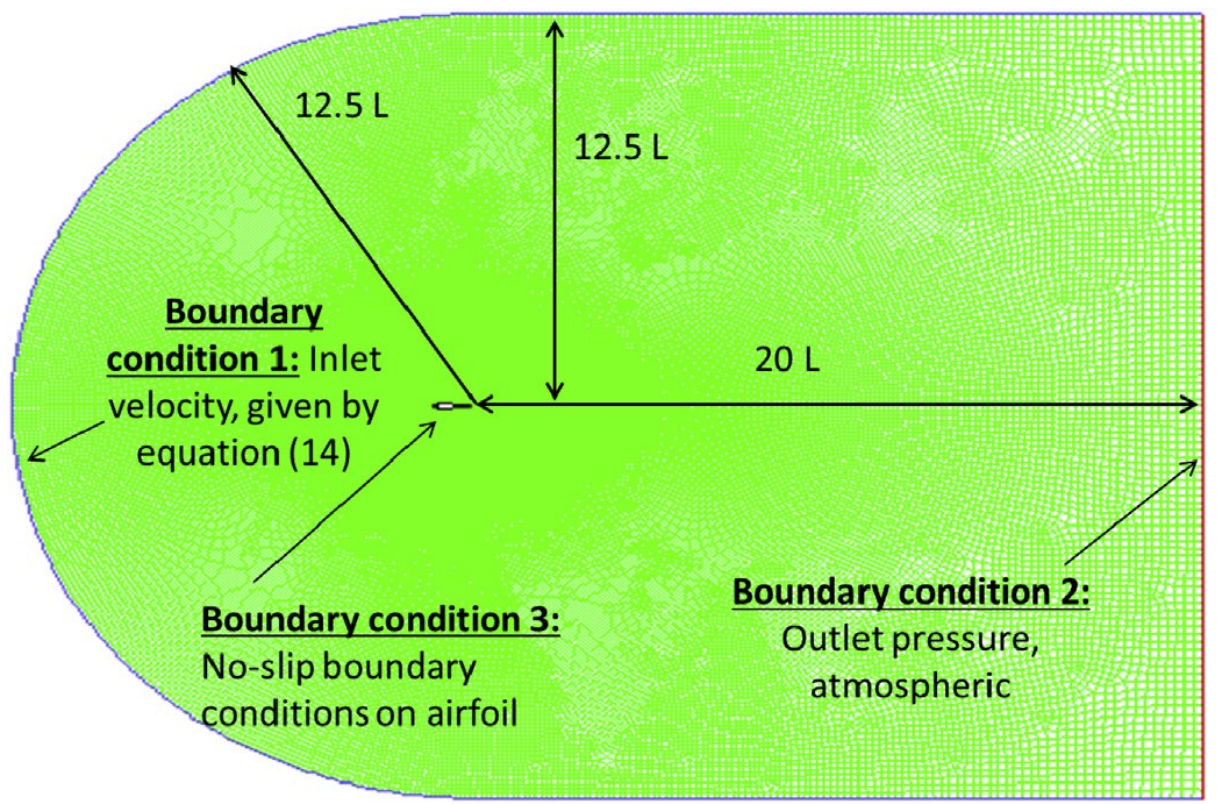

Figure (2) the dimensions of whole computational domain and location of airfoil
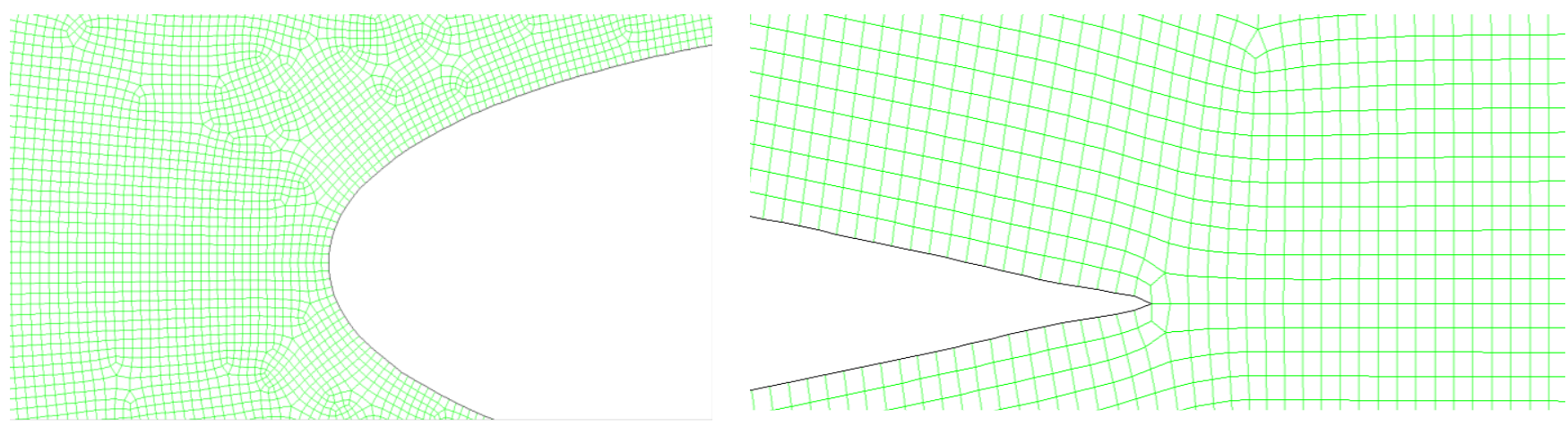

Figure 3. Computational grid near the wall of the airfoil 


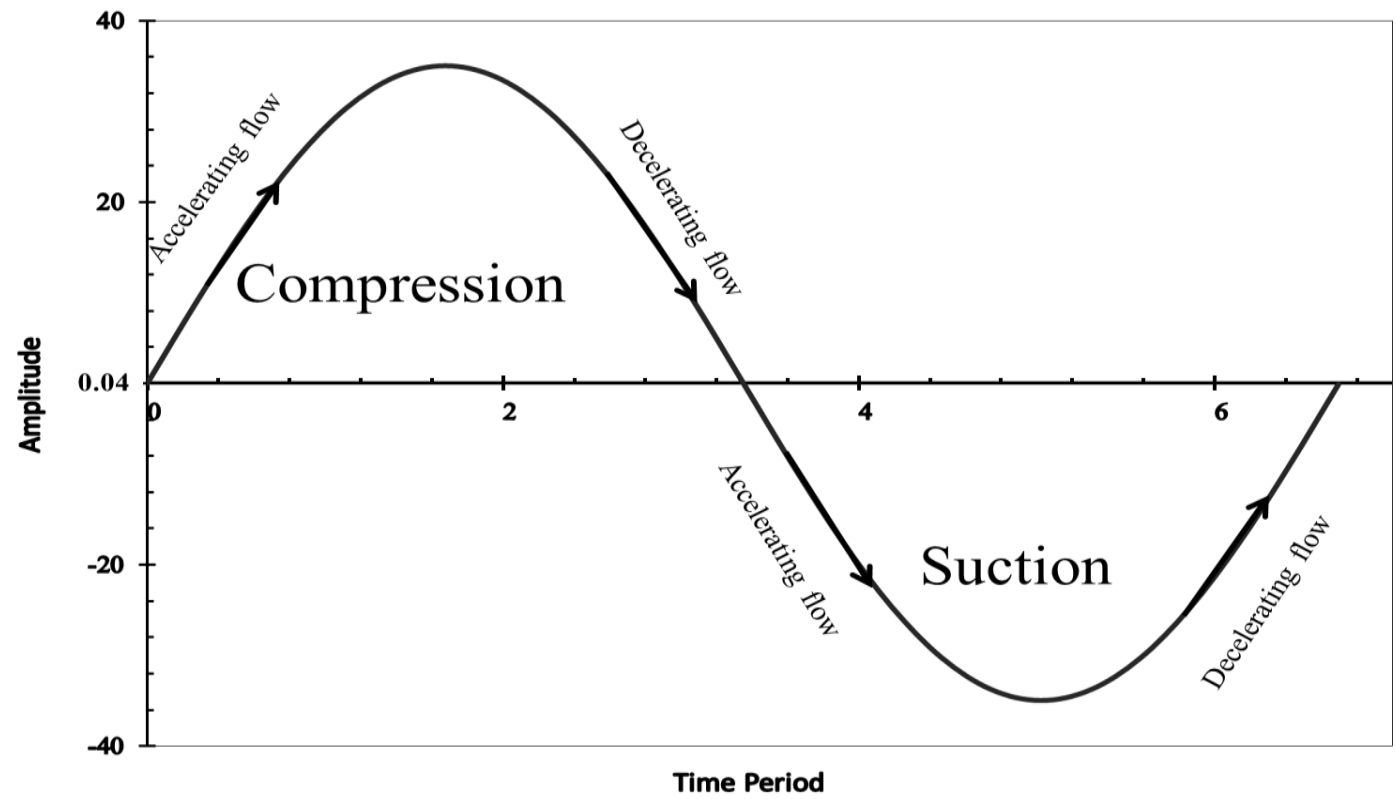

Figure 4.The sinusoidal wave boundary condition, which represent a regular oscillating water column

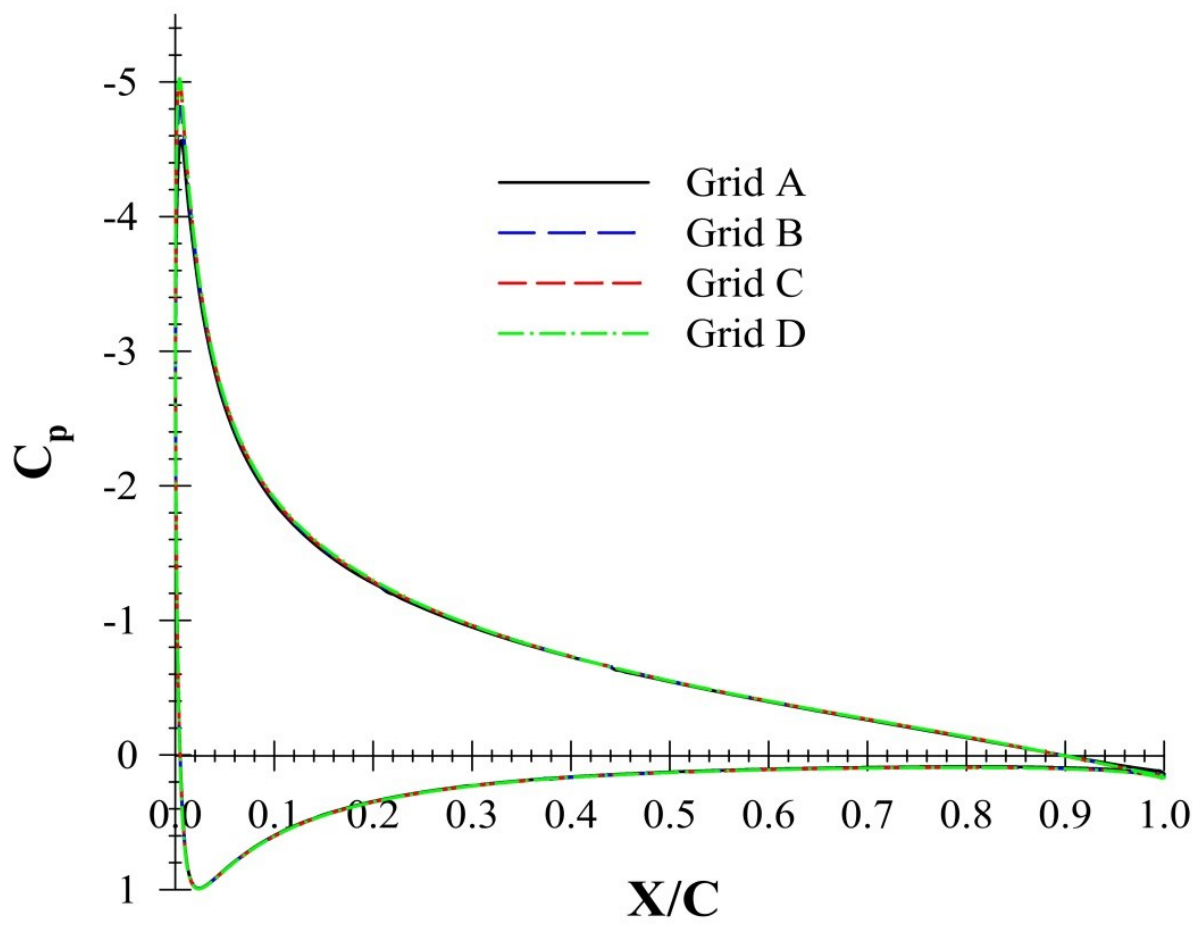

Figure 5. Pressure coefficient plotted on the normalized airfoil cord for different grid resolutions. 


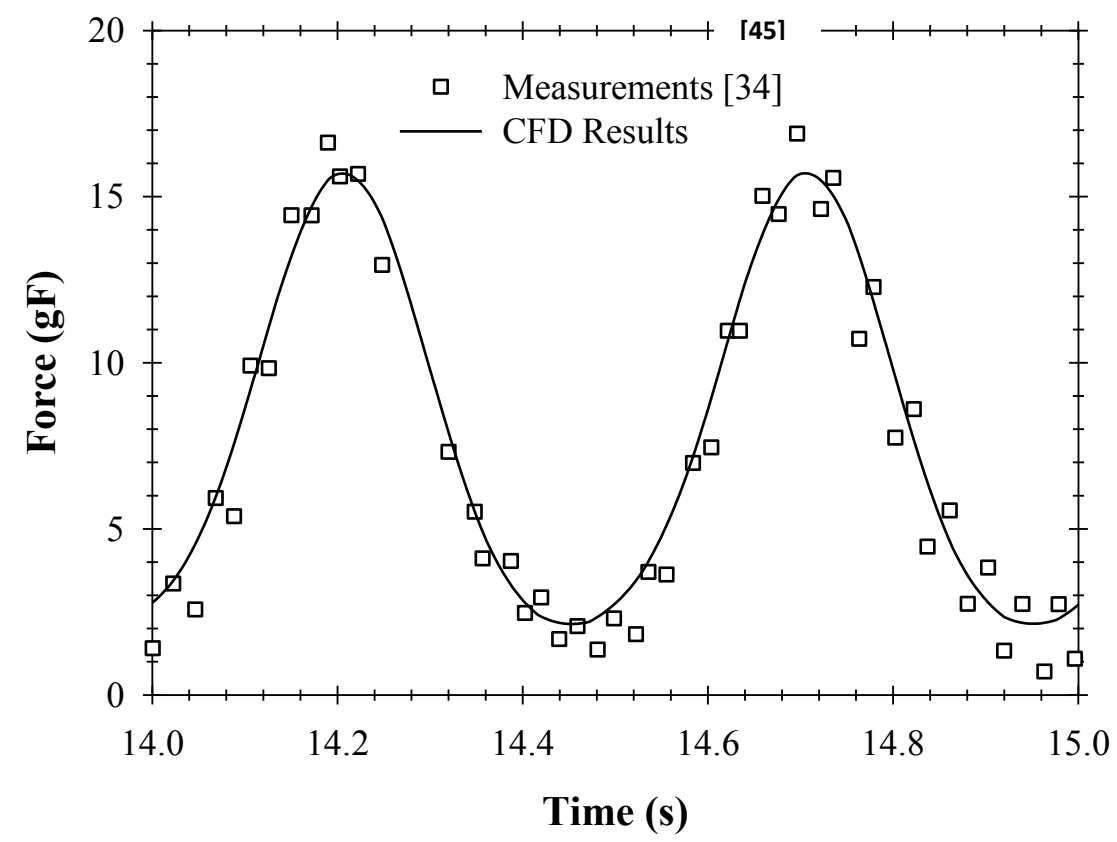

Figure 6(a) Measured unsteady in-line force $F_{D}$ (angle of attack= 0 degree) and $F_{D}$ calculated from CFD for frequency $2 \mathrm{~Hz}$.

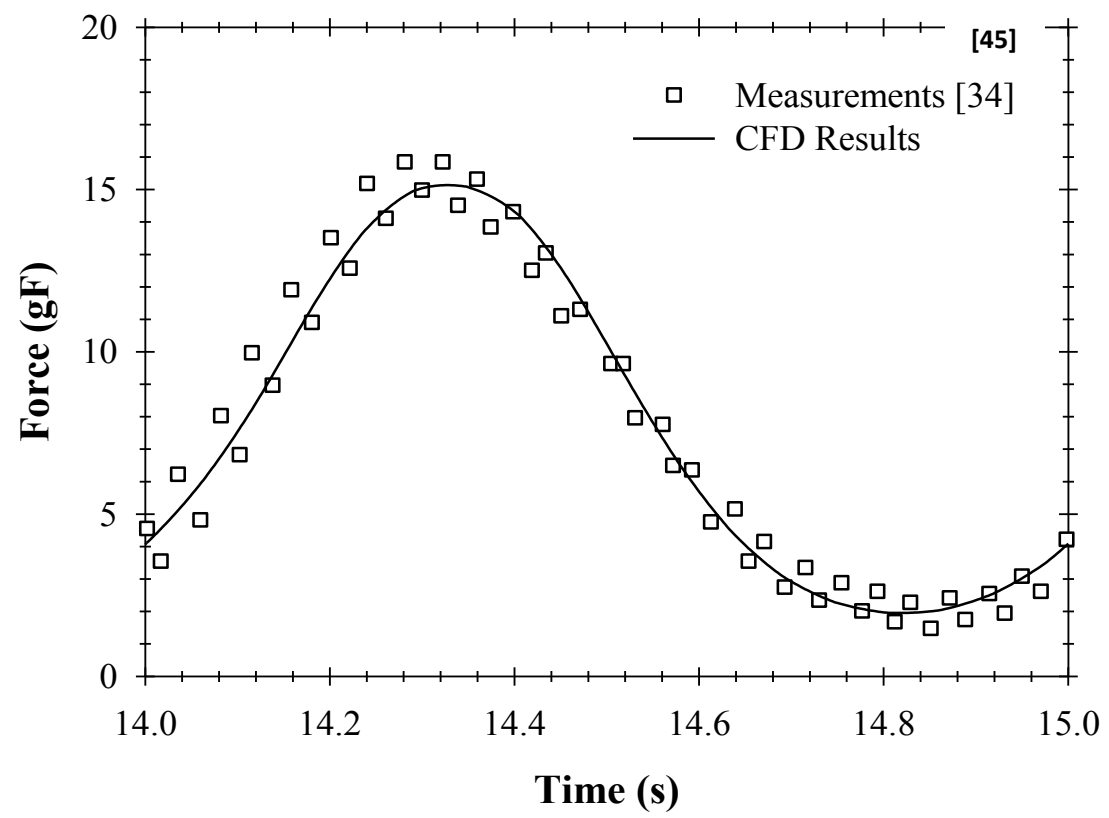

Figure 6(b) Measured unsteady in-line force $F_{D}$ (angle of attack= 0 degree) and $F_{D}$ calculated from CFD for frequency $1 \mathrm{~Hz}$. 


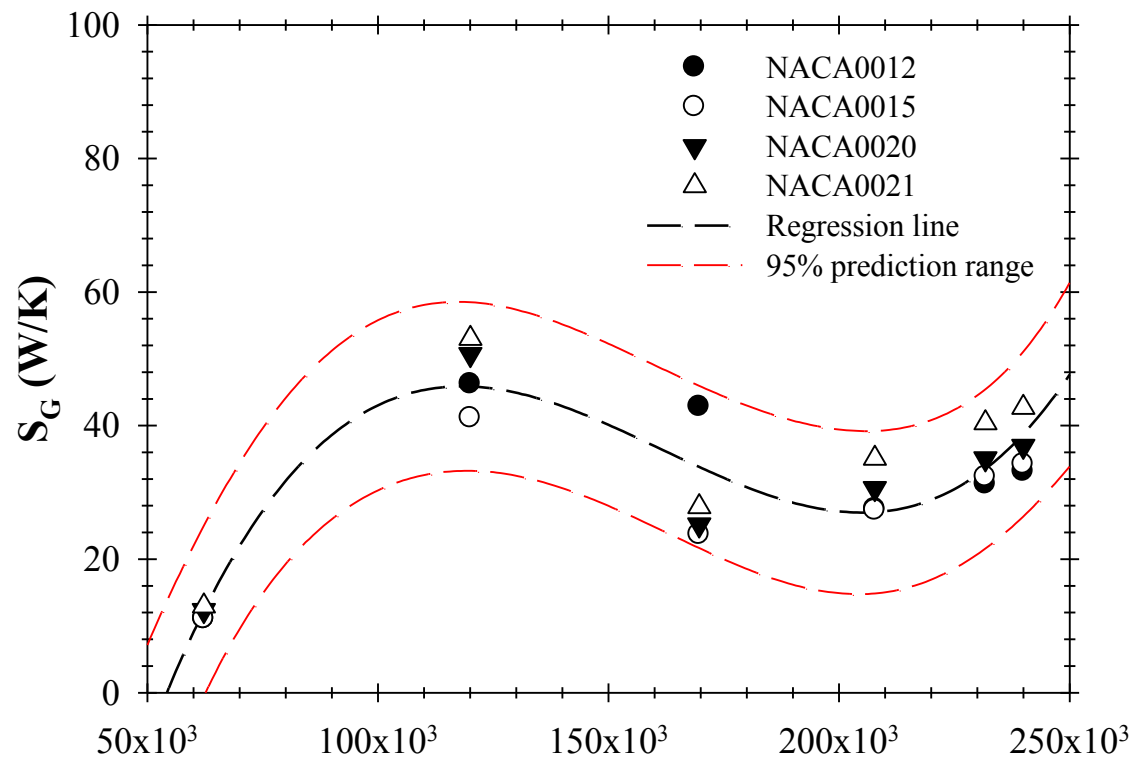

Reynolds number

Figure 7(a) the global entropy generation rate variation with different Reynolds's number at accelerating flow in compression cycle for four different airfoils

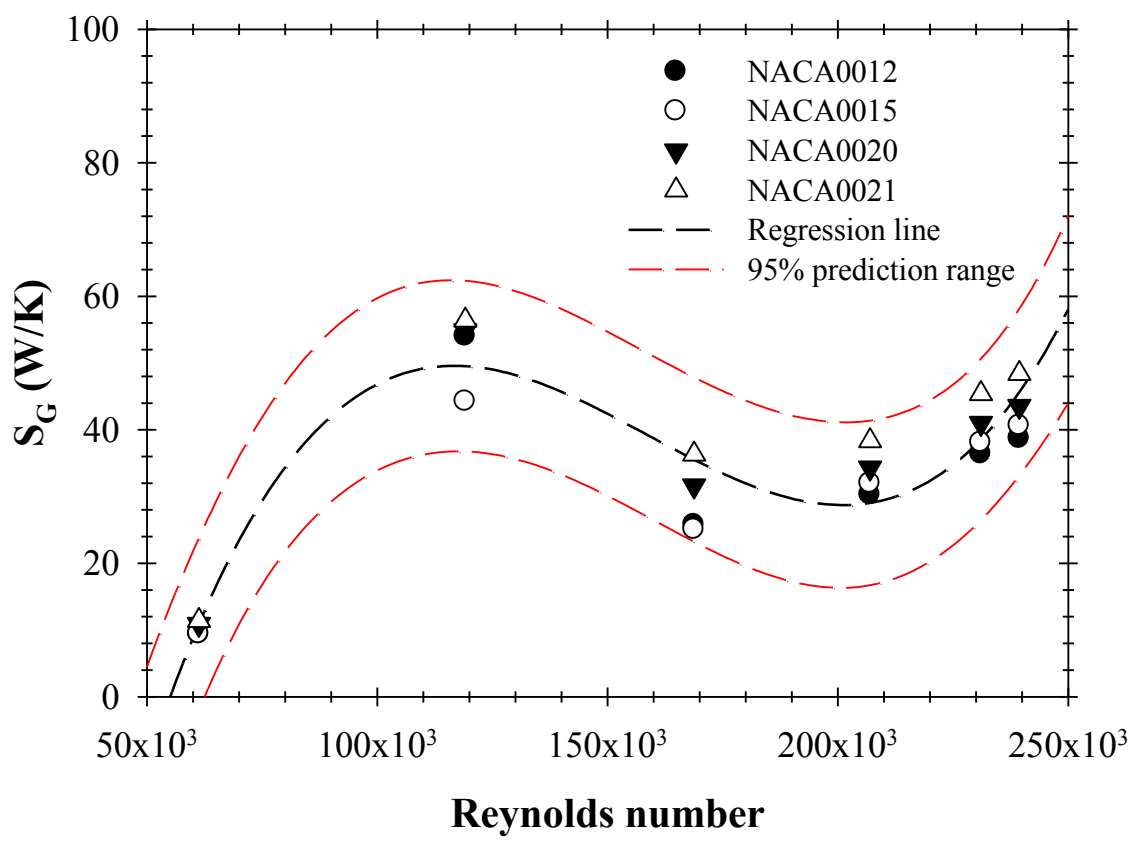

Figure 7(b) the global entropy generation rate variation with different Reynolds's number at accelerating flow in suction cycle for four different airfoils 


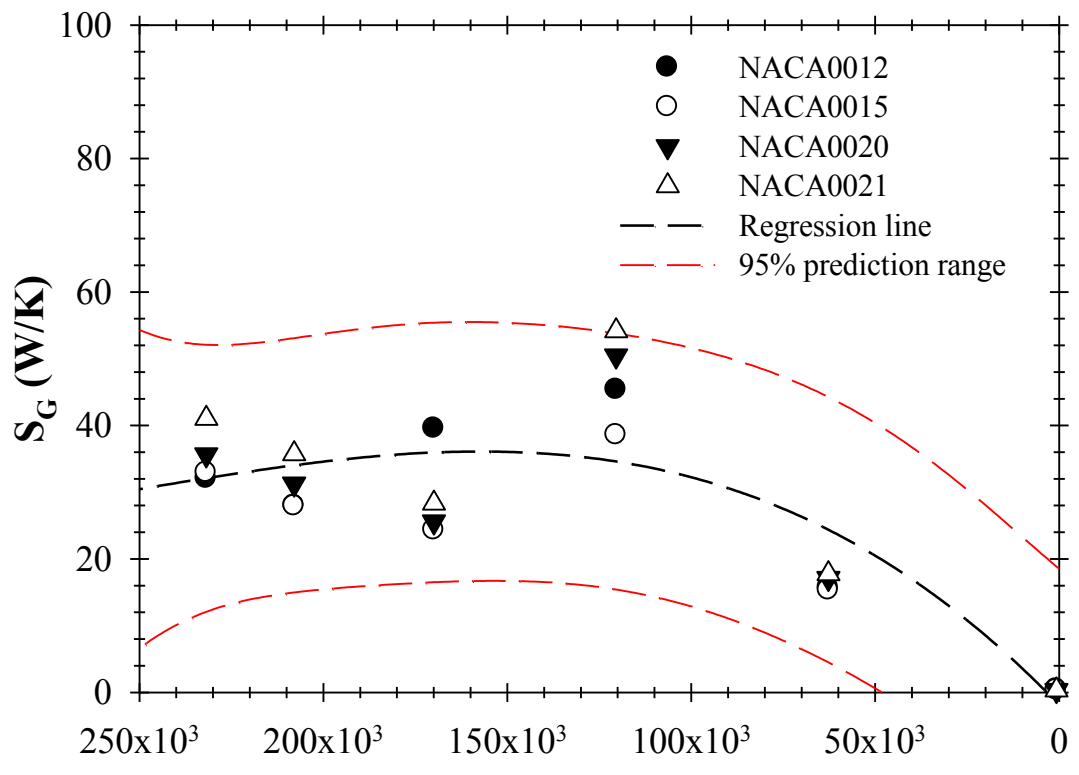

Reynolds number

Figure 8(a) the global entropy generation rate variation with different Reynolds's number at decelerating flow in compression cycle for four different airfoils

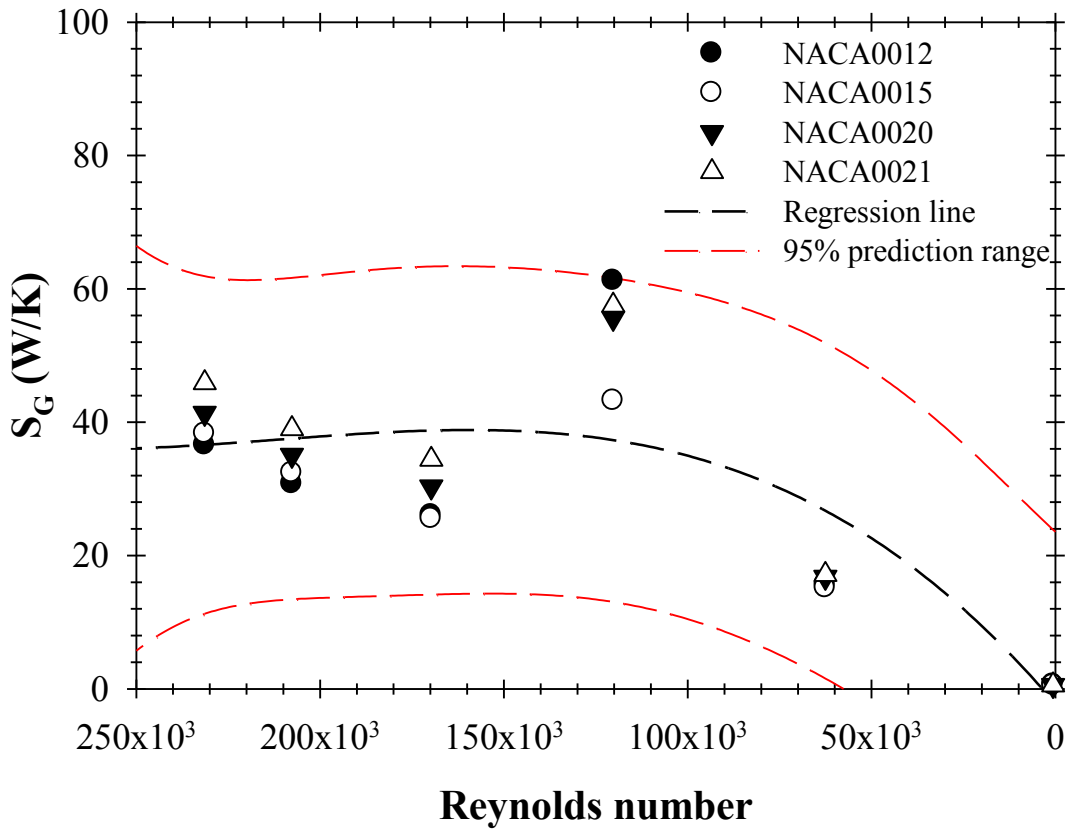

Figure 8(b) the global entropy generation rate with different Reynolds's number at decelerating flow in suction cycle for four different airfoils 


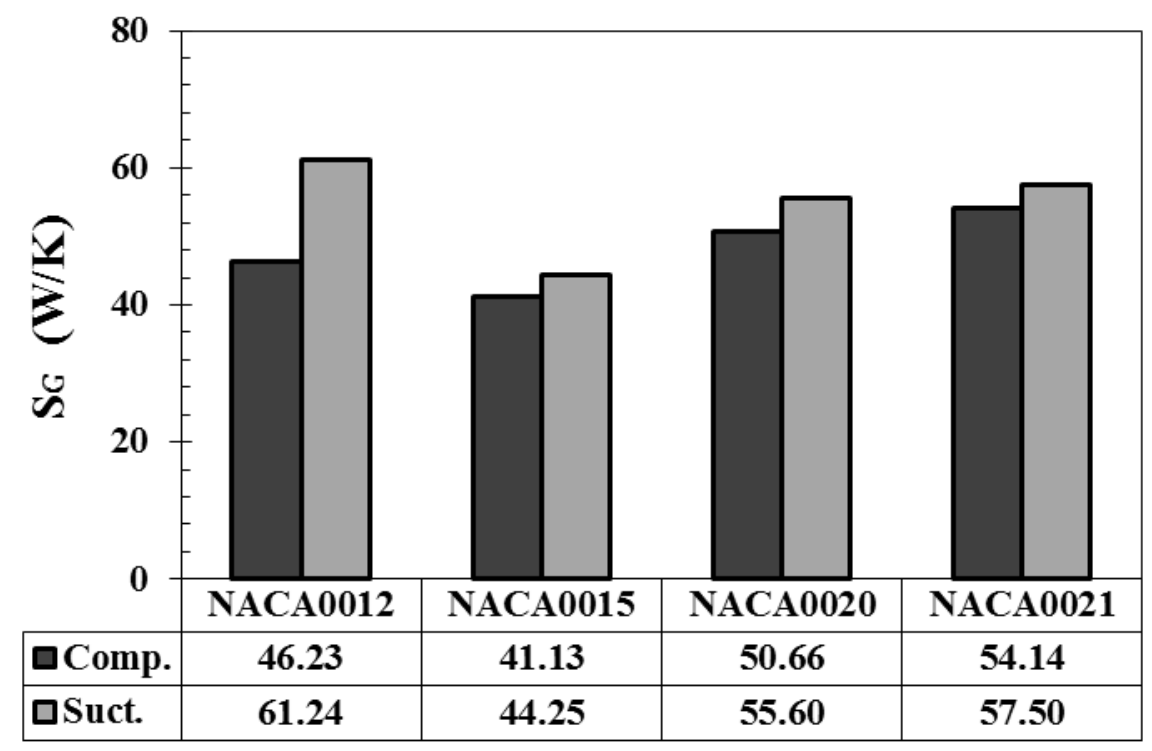

Figure 9 The maximum value for the global entropy generation rate at compression and suction cycle

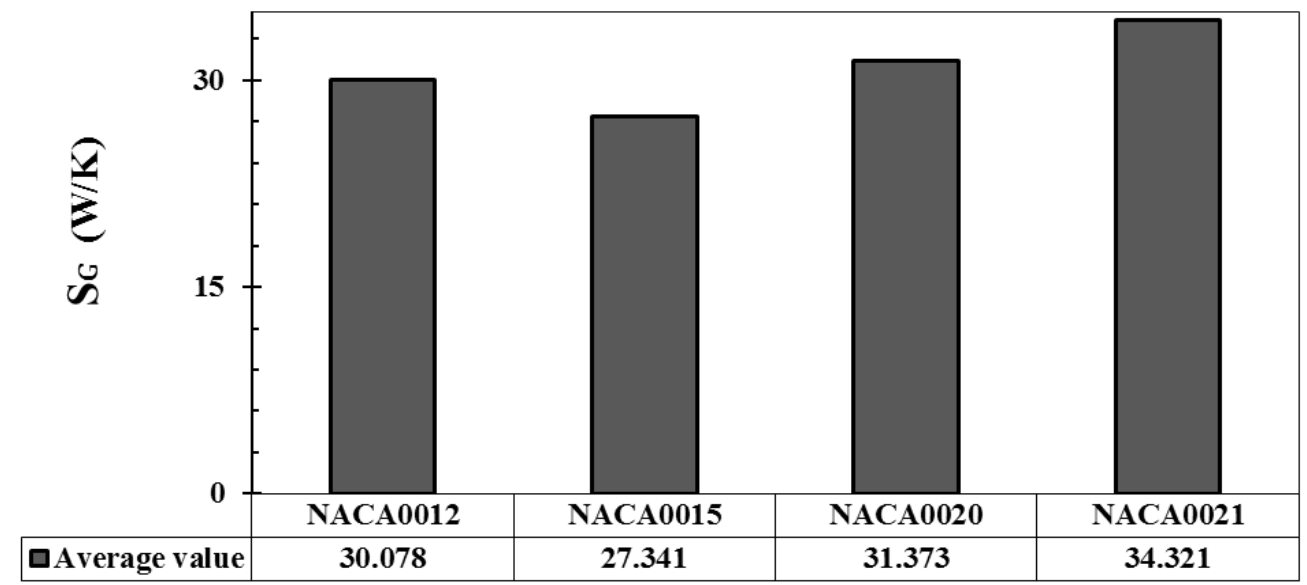

Figure 10 Comparisons between the global entropy generation rate during the sinusoidal wave cycle for four different airfoils 


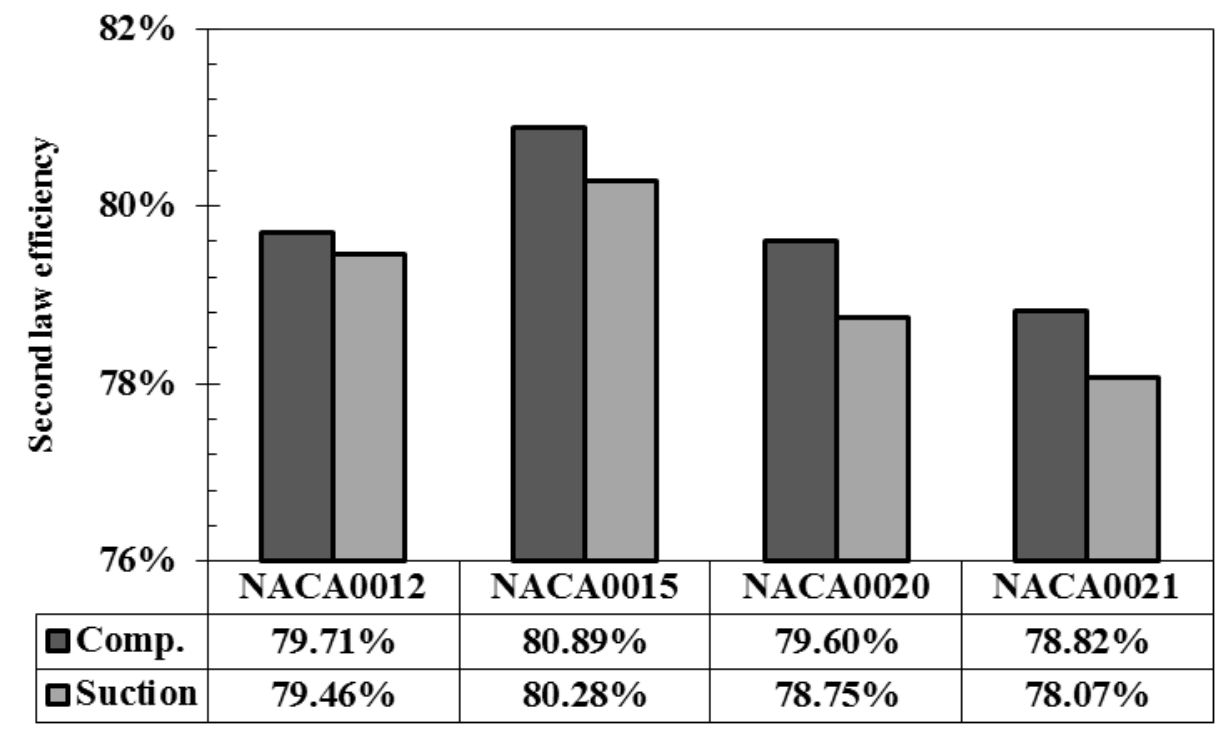

Figure 11 Comparisons between second law efficiency during the compression and suction wave cycle for four different airfoils

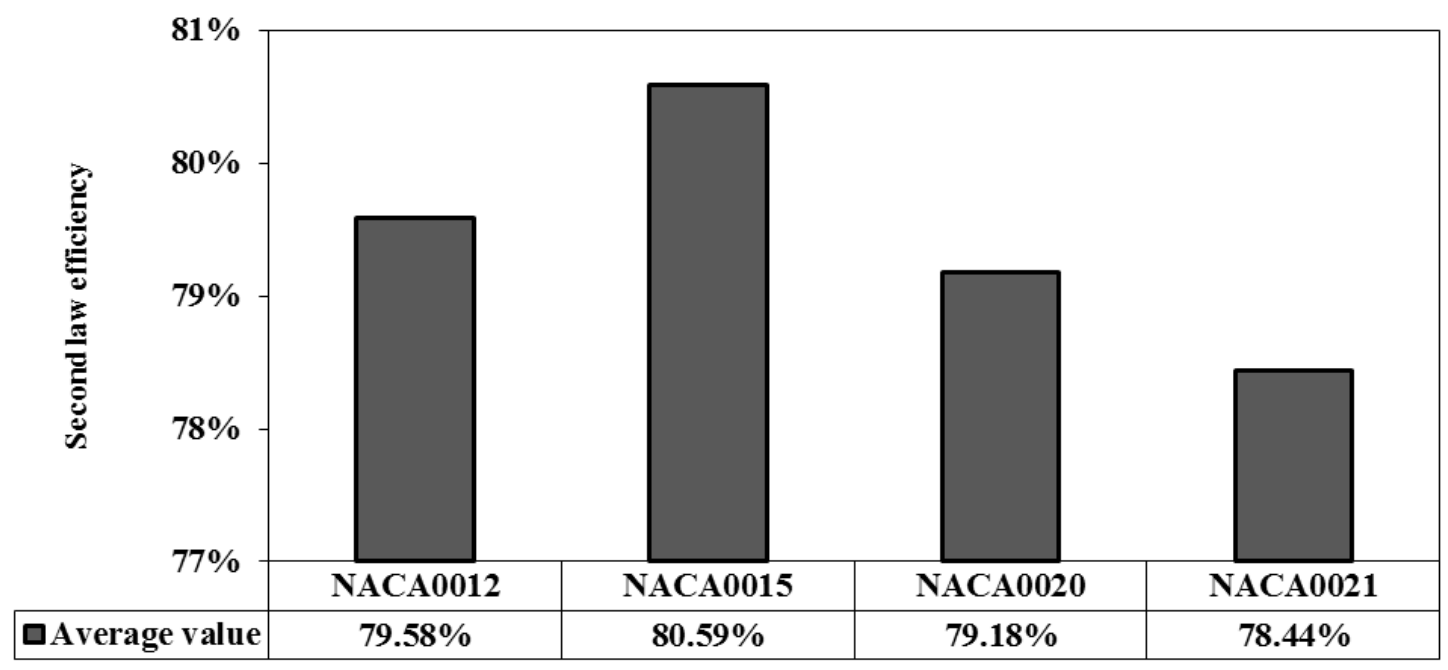

Figure 12 Comparisons between second law efficiency during the sinusoidal wave cycle for four different airfoils 

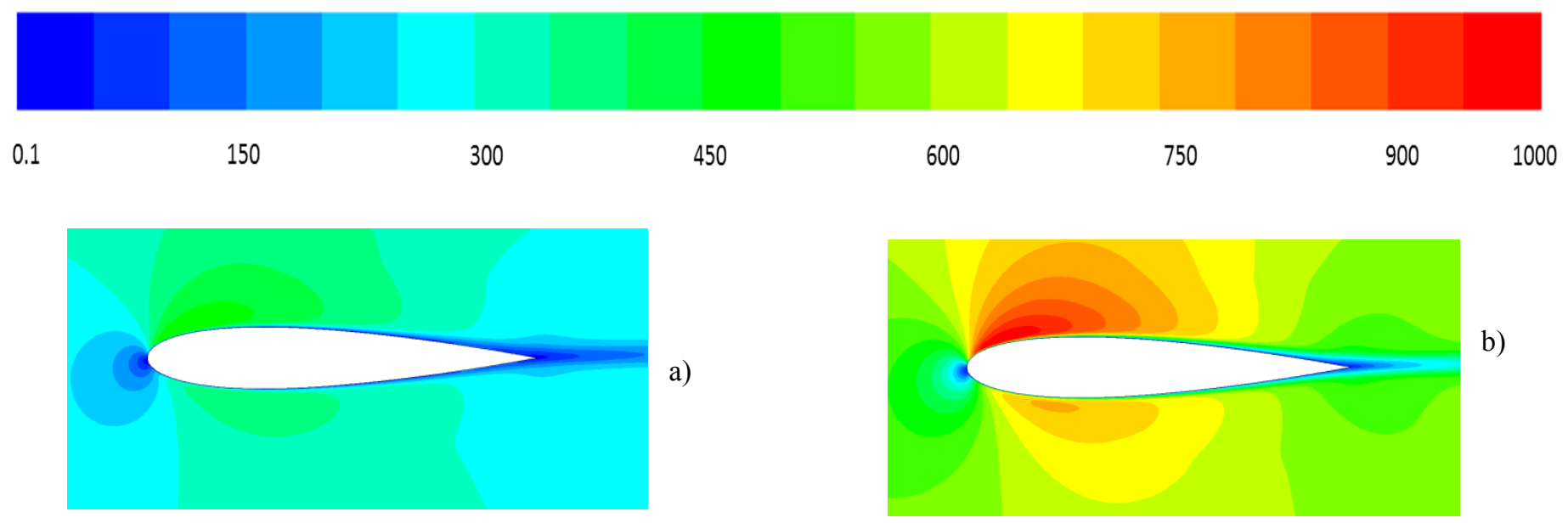

b)

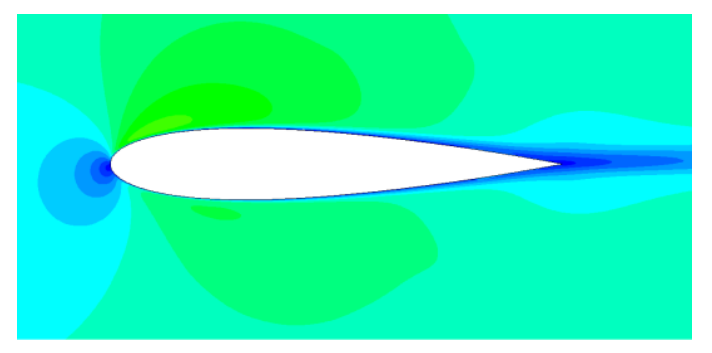

c)

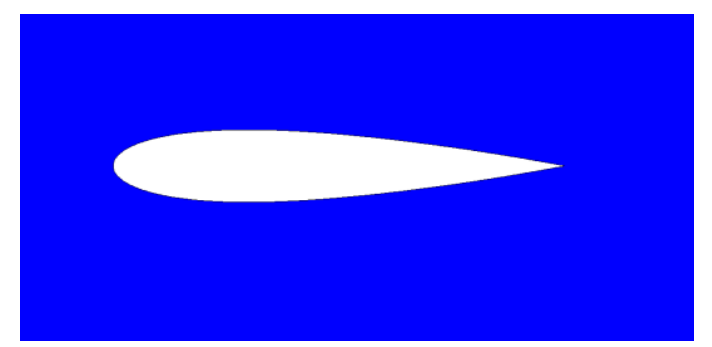

d)

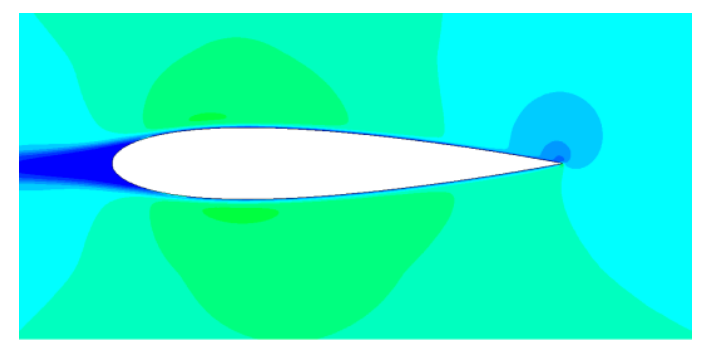

e)
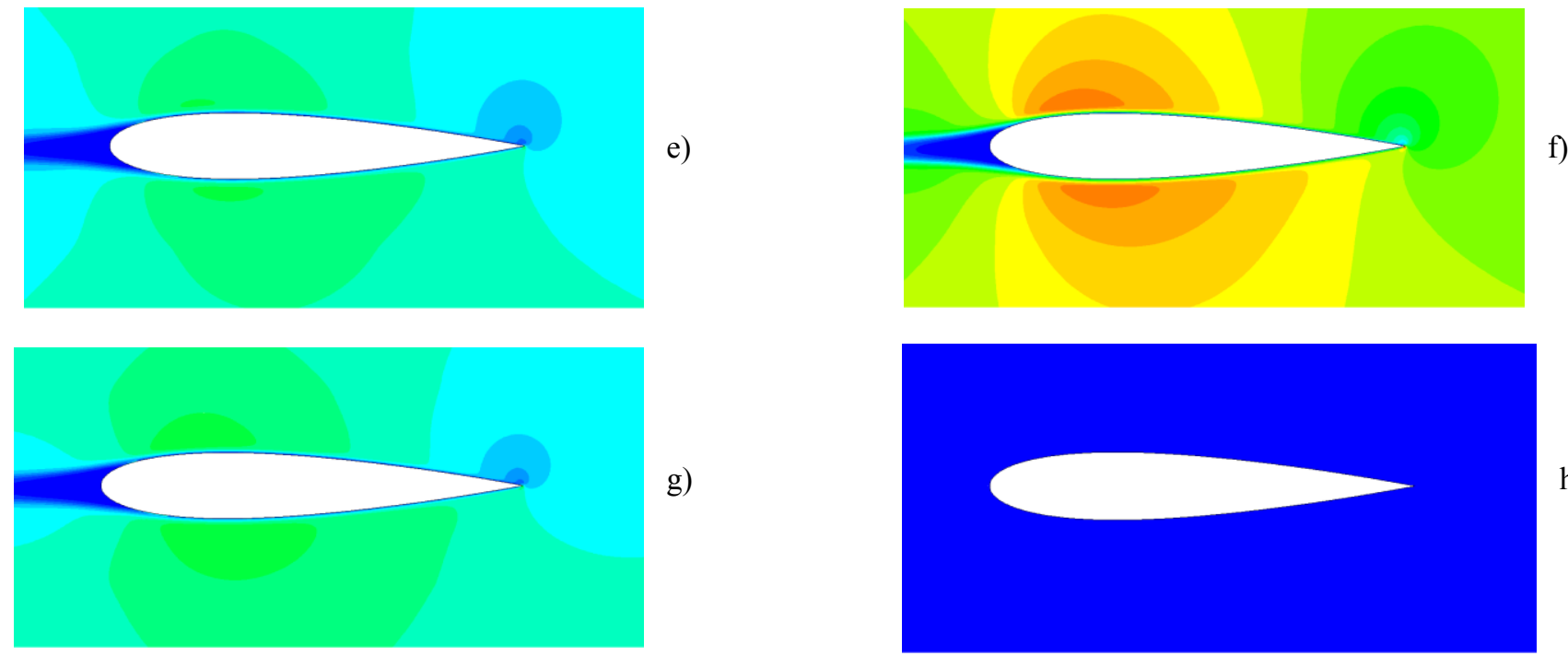

g)

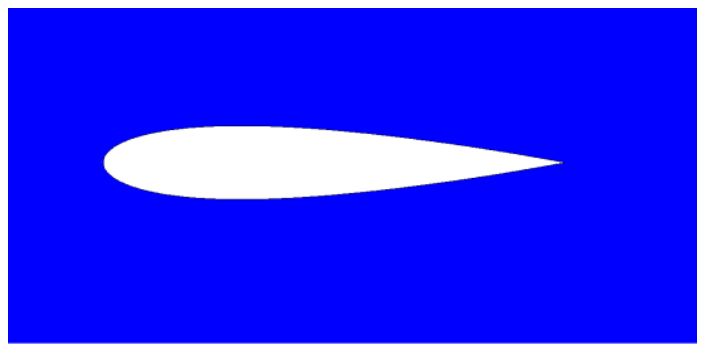

h)

Figure 13. Contours of Exergy around the blade of NACA0015 for angle of attack 2 degree at different time and different velocity along the sinusoidal wave, a) at $t=0.837 \mathrm{~s}$ and $V=24.778 \mathrm{~m} / \mathrm{s}$, b) $t=1.674 \mathrm{~s}$ and $V=35.04 \mathrm{~m} / \mathrm{s}$, c) $t=2.511 \mathrm{~s}$ and $V=24.824 \mathrm{~m} / \mathrm{s}$, d) $t=3.348 \mathrm{~s}$ and $V=\mathbf{0 . 1 0 5 6 5 ~ m / s , ~ e ) ~} t=4.185 \mathrm{~s}$ and $V=-24.7 \mathrm{~m} / \mathrm{s}, \mathbf{f}) t=5.022 \mathrm{~s} V=-35$ $\mathbf{m} / \mathbf{s}$, g) $t=5.859 \mathrm{~s}$ and $V=-24.79 \mathrm{~m} / \mathbf{s}$, h) $t=6.696 \mathrm{~s}$ and $V=-0.0913 \mathrm{~m} / \mathbf{s}$. 


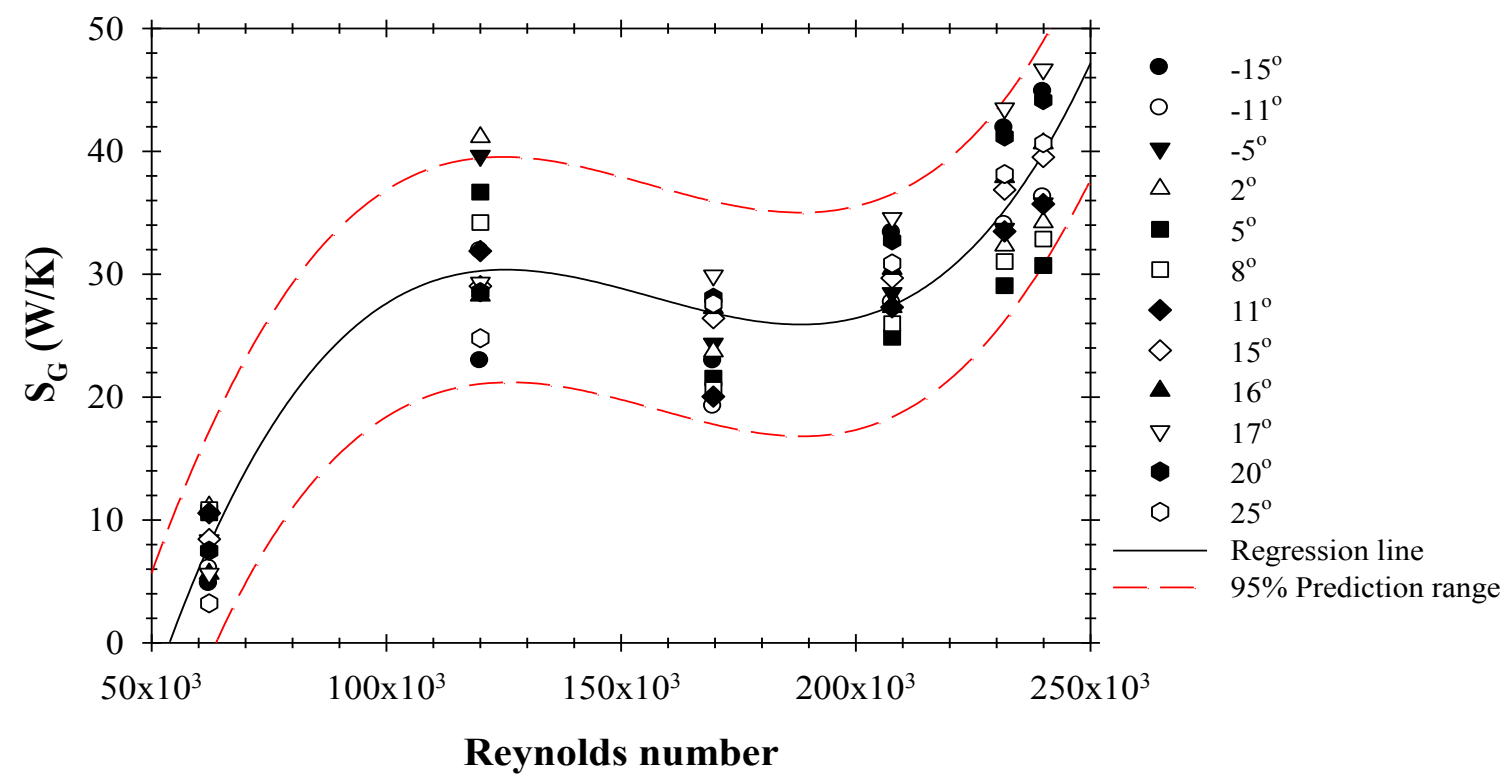

Figure 14 (a) the global entropy generation rate variation with different Reynolds's at accelerating flow in compression cycle for NACA0015 airfoil with different angle of attack.

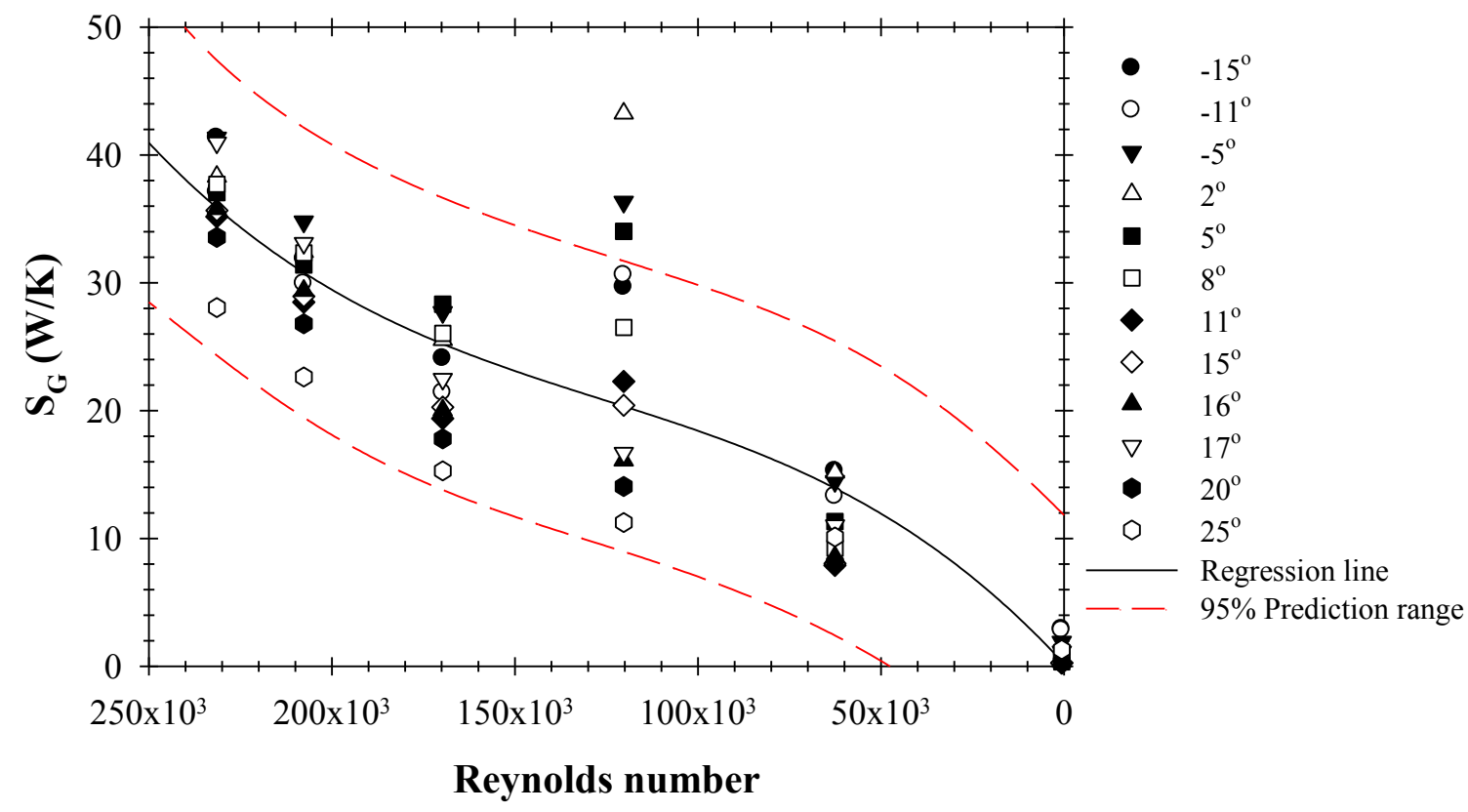

Figure 14 (b) the global entropy generation rate variations with different Reynolds's at decelerating flow in suction cycle for NACA0015 airfoil with different angle of attack. 


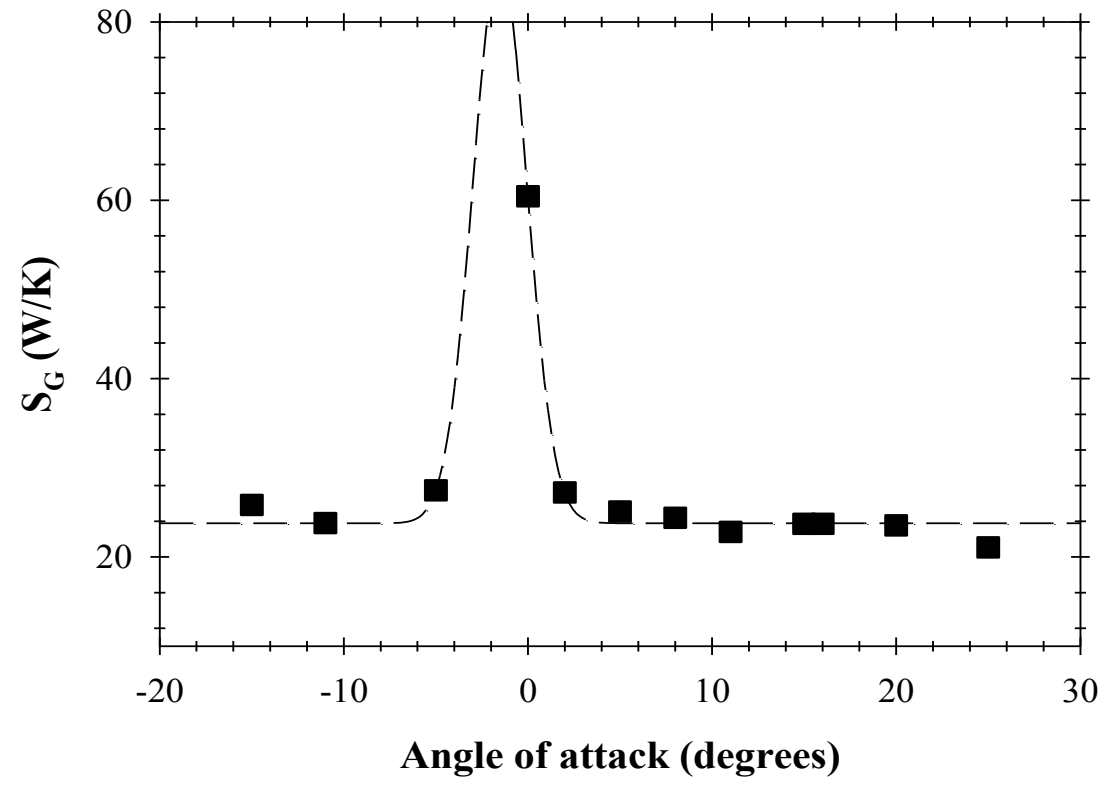

Figure 15 the global entropy generation rate during the sinusoidal wave cycle for different angle of attack. The dotted line indicates a fitting with a Gaussian distribution function.

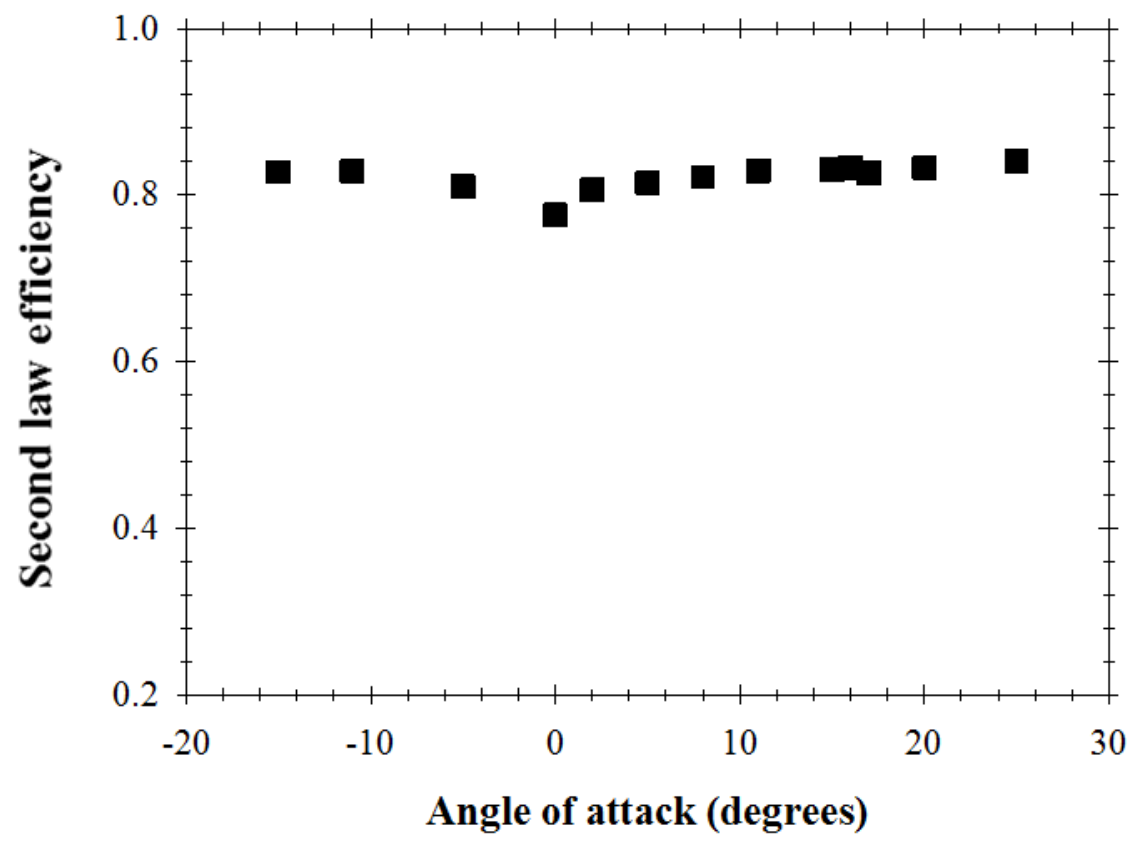

Figure 16 Second low efficiency during the sinusoidal wave cycle for different angle of attack 


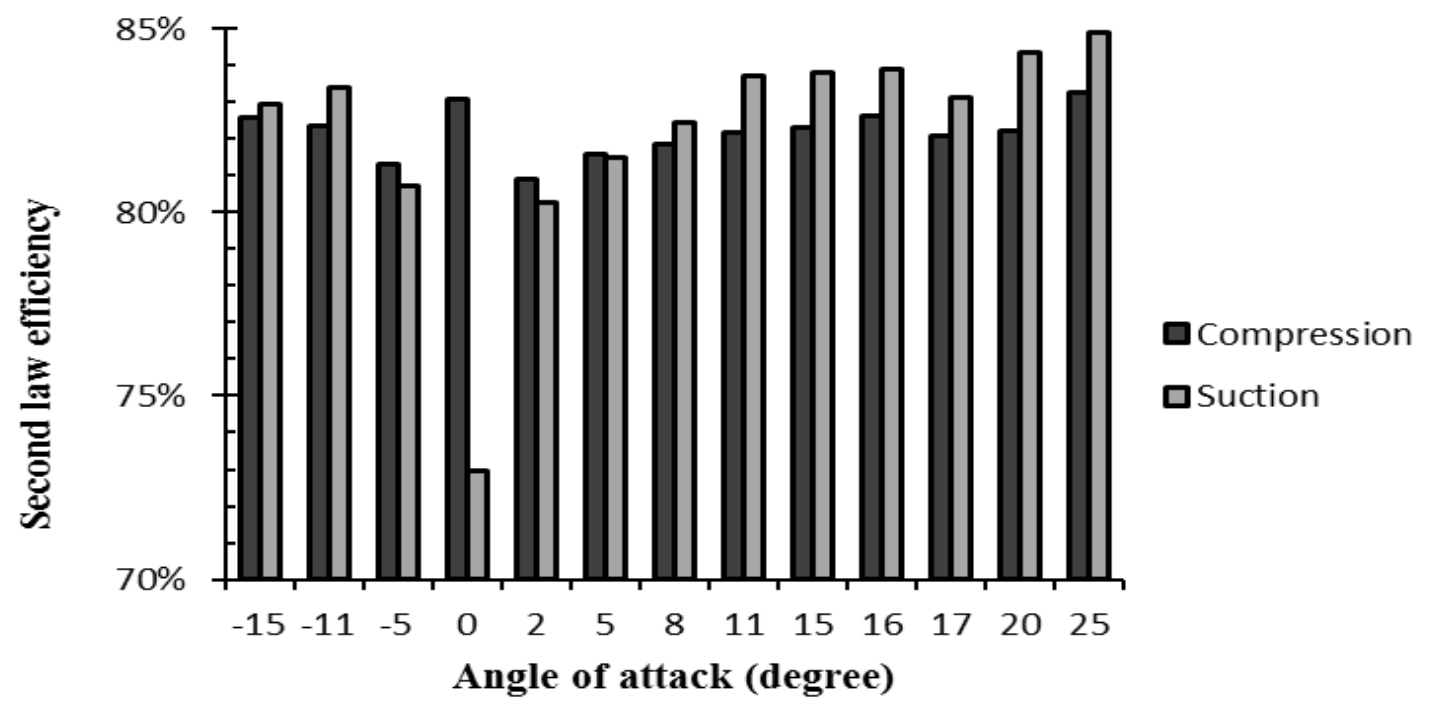

Figure 17 Comparisons between second law efficiency during the compression and suction wave cycle for different angle of attack 
Table 1 Specification of different grids used in the grid independence test

\begin{tabular}{|c|c|c|c|c|c|}
\hline Grid & No. of Cells & first cell & Growth rate & Aspect ratio & EquiAngle skew \\
\hline A & 112603 & $1 \times 10^{-4}$ & 1.02 & 1.996 & 0.429 \\
\hline B & 200017 & $1 \times 10^{-5}$ & 1.015 & 2.466 & 0.475 \\
\hline C & 312951 & $1 \times 10^{-5}$ & 1.012 & 2.376 & 0.514 \\
\hline D & 446889 & $1 \times 10^{-6}$ & 1.01 & 2.551 & 0.513 \\
\hline
\end{tabular}

Table 2 the direction for positive and negative value of angle of attack.

\begin{tabular}{|c|c|c|}
\hline Angle of attack & x component of velocity direction & y component of velocity direction \\
\hline $\mathbf{- 1 5}$ & 0.965926 & -0.258819 \\
\hline $\mathbf{- 1 1}$ & 0.981627 & -0.190809 \\
\hline $\mathbf{- 5}$ & 0.996195 & -0.087156 \\
\hline $\mathbf{0}$ & 1 & 0 \\
\hline $\mathbf{2}$ & 0.999391 & 0.0348995 \\
\hline $\mathbf{5}$ & 0.996195 & 0.139173 \\
\hline $\mathbf{8}$ & 0.990268 & 0.190809 \\
\hline $\mathbf{1 1}$ & 0.981627 & 0.258819 \\
\hline $\mathbf{1 5}$ & 0.965926 & 0.275637 \\
\hline $\mathbf{1 6}$ & 0.961262 & 0.292372 \\
\hline $\mathbf{1 7}$ & 0.956305 & 0.342020 \\
\hline $\mathbf{2 0}$ & 0.939693 & 0.422618 \\
\hline $\mathbf{2 5}$ & 0.906308 & \\
\hline & & \\
\hline
\end{tabular}

